Supporting Information

\title{
A Manganese(IV)-Hydroperoxo Intermediate Generated by Protonation of the Corresponding Manganese(III)-Superoxo Complex
}

\author{
Yen-Hao Lin, ${ }^{\dagger}$ Y ury Kutin, ${ }^{\star}$, Maurice van Gastel,${ }^{\perp}$ Eckhard Bill, ${ }^{*}$ Alexander Schnegg,,$*$ \\ Shengfa Ye, ${ }^{*, \perp, \infty}$ and Way-Zen Lee*,†,\# \\ ${ }^{\dagger}$ Department of Chemistry, National Taiwan Normal University, Taipei 11677, Taiwan \\ ${ }^{\ddagger}$ Max-Planck-Institut für Chemische Energiekonversion, Mülheim an der Ruhr D-45470, \\ Germany \\ ${ }^{\perp}$ Max-Planck-Institut für Kohlenforschung, Mülheim an der Ruhr D-45470, Germany \\ ${ }^{\infty}$ State Key Laboratory of Catalysis, Dalian Institute of Chemical Physics, Chinese \\ Academy of Sciences, Dalian 116023, China \\ ${ }^{\#}$ Department of Medicinal and Applied Chemistry, Kaohsiung Medical University, \\ Kaohsiung 807, Taiwan
}

*Corresponding author. Email: wzlee@ ntnu.edu.tw (W.-Z.L); shengfa.ye@dicp.ac.cn, shengfa.ye@kofo.mpg.de (S.Y.); alexander.schnegg@ cec.mpg.de (A.S.)

§Present address of Y.K.: Department of Chemistry and Chemical Biology, TU Dortmund University, D-44227 Dortmund, Germany

Contents

Figures S1-S20

Tables S1-S3

References 1-29 


\section{Materials and Methods}

All manipulations were operated under a nitrogen or argon atmosphere using standard Schlenk techniques or in a glovebox. Acetonitrile and dichloromethane were distilled under nitrogen over $\mathrm{CaH}_{2}$ prior to use; THF, MeTHF, Pentane and diethyl-ether were purified by $\mathrm{Na}$ /benzophenone and distilled prior to use. n-PrCN was purified using $\mathrm{Na}_{2} \mathrm{CO}_{3}$ and $\mathrm{KMnO}_{4}$, and then distilled prior to use. $\mathrm{Mn}\left(\mathrm{BDP}^{\mathrm{Br}} \mathrm{P}\right), \mathrm{Mn}\left(\mathrm{BDP}^{\mathrm{Br}} \mathrm{P}\right)\left(\mathrm{O}_{2}{ }^{\circ}\right)$ (2) and $\mathrm{Mn}\left(\mathrm{BDP}^{\mathrm{Br}} \mathrm{P}\right)(\mathrm{OOH})(3)$ were prepared by adapting a literature method. ${ }^{1}$ Other chemical reagents were obtained from commercial sources and used as received unless stated otherwise. UV-vis spectra were recorded with Agilent 8454 spectrophotometer equipped with cryostat from Unisoku Scientific Instruments, Osaka, Japan.

\section{Resonance Raman Collections}

Resonance Raman spectra were recorded on a TriVista 555 triple monochromator equipped with a liquid-nitrogen-cooled Roper Scientific 400BR Excelon CCD camera. A light source with an excitation wavelength of $594 \mathrm{~nm}$ and power of $20 \mathrm{~mW}$ from a cobalt solid-state laser was used. The solution of a sample was packed into a quartz EPR tube and measured in an EPR quartz finger Dewar which was cooled with liquid nitrogen. The Raman signal was collected in a $180^{\circ}$ backscattering geometry with a Thorlabs MPD249HP01 off-axis parabolic mirror and focused onto the entrance slit of a spectrograph with a $100 \mathrm{~mm}$ diameter $\mathrm{f} / 4$ lens. The scattered light was dispersed with a grating of $1,800 \mathrm{~mm}^{-1}$ and further with two filter prestages of $900 \mathrm{~mm}^{-1}$. The slit widths at the first and third stages amounted to $100 \mu \mathrm{m}$, thus providing a spectral resolution at the CCD camera of about $0.8 \mathrm{~cm}^{-1}$. Spectra were collected for about $30 \mathrm{~min}$ for a given wavelength and spectral window. Calibration of the Raman shifts has been achieved to an accuracy of $1 \mathrm{~cm}^{-1}$ by using $\mathrm{Na}_{2} \mathrm{SO}_{4}$ as well as the solvent signals as references.

\section{EPR Spectroscopy}

$\mathrm{X}$-Band CW EPR measurements were performed in the temperature range of 3.8 to $12 \mathrm{~K}$ using a Bruker E500 spectrometer equipped with a Bruker ER 4116DM resonator, Oxford Instruments ESR 935 gas flow cryostat and Oxford Instruments ITC503 temperature controller. Microwave power was in the range of 0.2 to $1 \mathrm{~mW}$. Magnetic field modulation amplitude was 10.0 G. Q-band pulse EPR measurements were performed at $\mathrm{T}=9 \mathrm{~K}$ using a Bruker ELEXSYS E580 Q-band EPR spectrometer equipped with a homebuilt TE011 microwave resonator, ${ }^{2}$ Oxford Instruments ESR 935 gas flow cryostat and Oxford Instruments ITC504 temperature controller. Field-swept EPR spectra were obtained via integration of the electron spin echo (ESE) signal. The length of the $\pi$-pulse was $32 \mathrm{~ns}$, inter-pulse delay was $280 \mathrm{~ns}$ and shot repetition time (SRT) was $50 \mathrm{~ns}$. Simulations of EPR spectra were performed using the EasySpin toolbox ${ }^{3}$ for MATLAB ${ }^{\circledR}$.

\section{Computational Details}

All calculations were performed by using the ORCA quantum chemical program package. ${ }^{4}$ Geometry optimizations and frequency analyses were performed with the BP86 density functional. The def2-TZVP for the first coordination sphere and def2-SVP basis sets $^{6}$ for the remaining atoms were applied in combination with the auxiliary basis sets $\operatorname{def} 2 / \mathrm{J}^{7}$ The $\mathrm{RI}^{8}$ approximation was used to accelerate the calculations. EPR parameters were computed by using the $\mathrm{B}^{3} \mathrm{LYP}^{9}$ density functional in conjunction with the $\mathrm{CP}(\mathrm{PPP})^{10}$ basis set for Mn and the def2-TZVP basis set for remaining atoms. The magnetic hyperfine 
coupling matrix, A, of the ${ }^{55} \mathrm{Mn}$ center was calculated by taking the isotropic Fermi contact term, the first order traceless dipolar contribution and the second order non-traceless orbital contribution into account. The Fermi-contact contributions were scaled by a factor of $1.59 .{ }^{11}$ Orbital contributions to the hyperfine tensors were calculated as second order properties employing the coupled perturbed (CP) Kohn-Sham theory. ${ }^{12}$ The contributions of spin orbit coupling (SOC) to the zero-field splitting (ZFS) ${ }^{13}$ were calculated by linear response theory. ${ }^{14}$ The spin-spin coupling contributions to ZFSs are calculated from the equation of McWeeny and Mizuno (Eq. 1), ${ }^{15}$

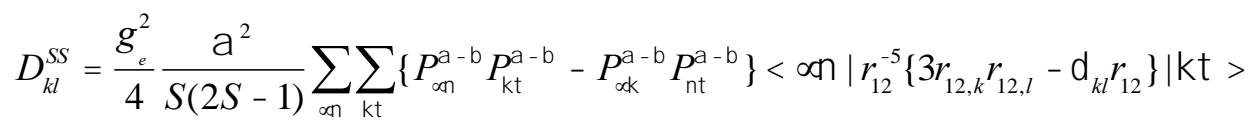

in which spin density matrix $\mathrm{P}^{\alpha-\beta}$ was obtained on the basis of the spin-unrestricted natural orbital (UNO) determinant. ${ }^{16}$ 


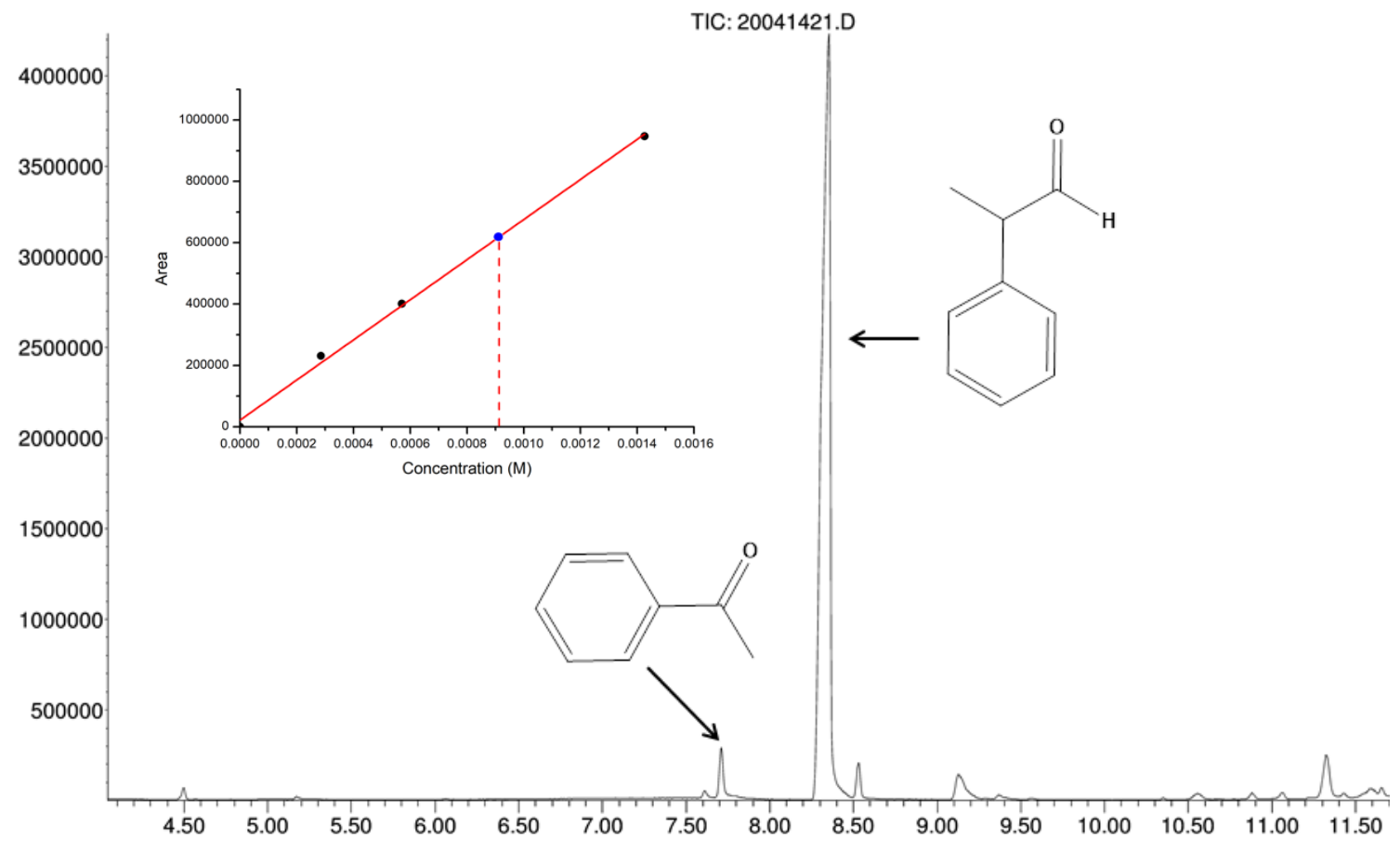

Figure S1. GC-MS analyses showing the acetophenone product of the reaction of $\mathrm{Mn}^{\mathrm{III}}\left(\mathrm{BDP}^{\mathrm{Br}} \mathrm{P}\right)\left(\mathrm{O}_{2}{ }^{\circ}\right)(2)(1.0 \mathrm{mM}$, orange $)$ with 100 equiv of $2-\mathrm{PPA}$ in THF at $-80{ }^{\circ} \mathrm{C}$ in 7.5 hrs. The inset shows the acetophenone product in $92 \%$ yield relative to $\mathbf{2}$ obtained from a calibration curve. 


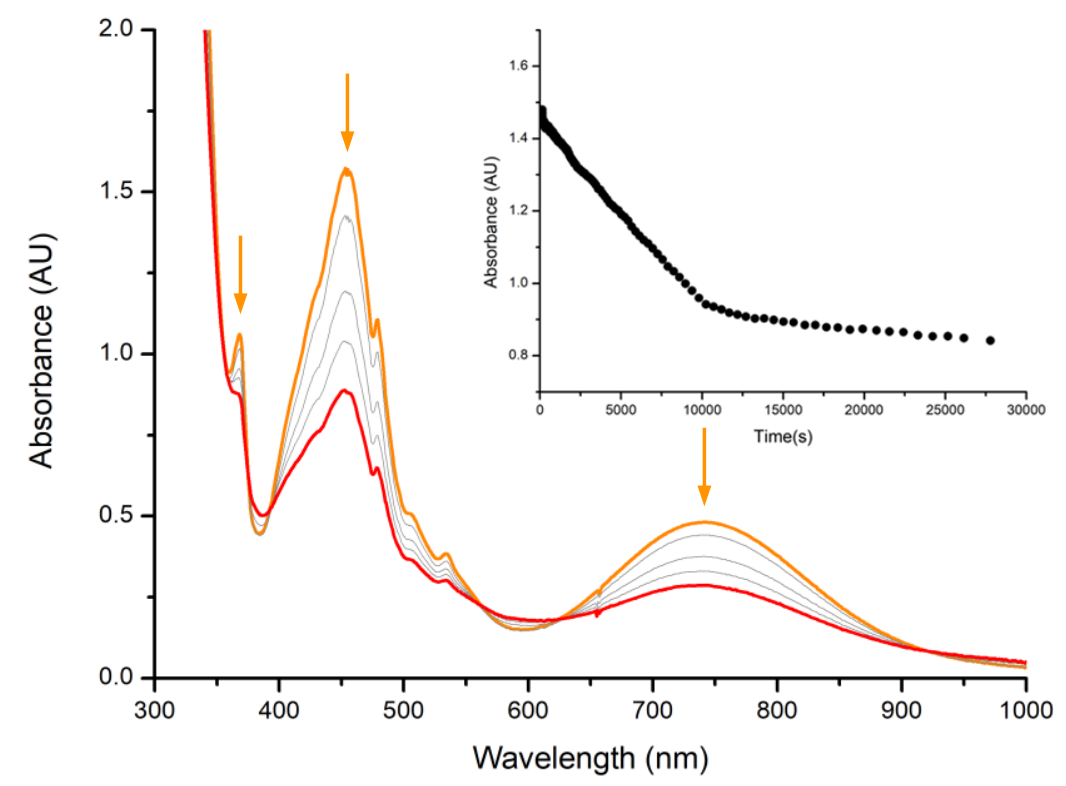

Figure S2. UV-vis spectral changes of the reaction of $\mathrm{Mn}^{\mathrm{III}}\left(\mathrm{BDP}^{\mathrm{Br}} \mathrm{P}\right)\left(\mathrm{O}_{2}{ }^{\circ}\right)(\mathbf{2})(1.0 \mathrm{mM}$, orange) with 100 equiv of 2-PPA in THF at $-80^{\circ} \mathrm{C}$ in $7.5 \mathrm{hrs}$. The inset shows time profile of the natural decay of $\mathbf{2}$ in the aforementioned reaction monitored at $450 \mathrm{~nm}$.

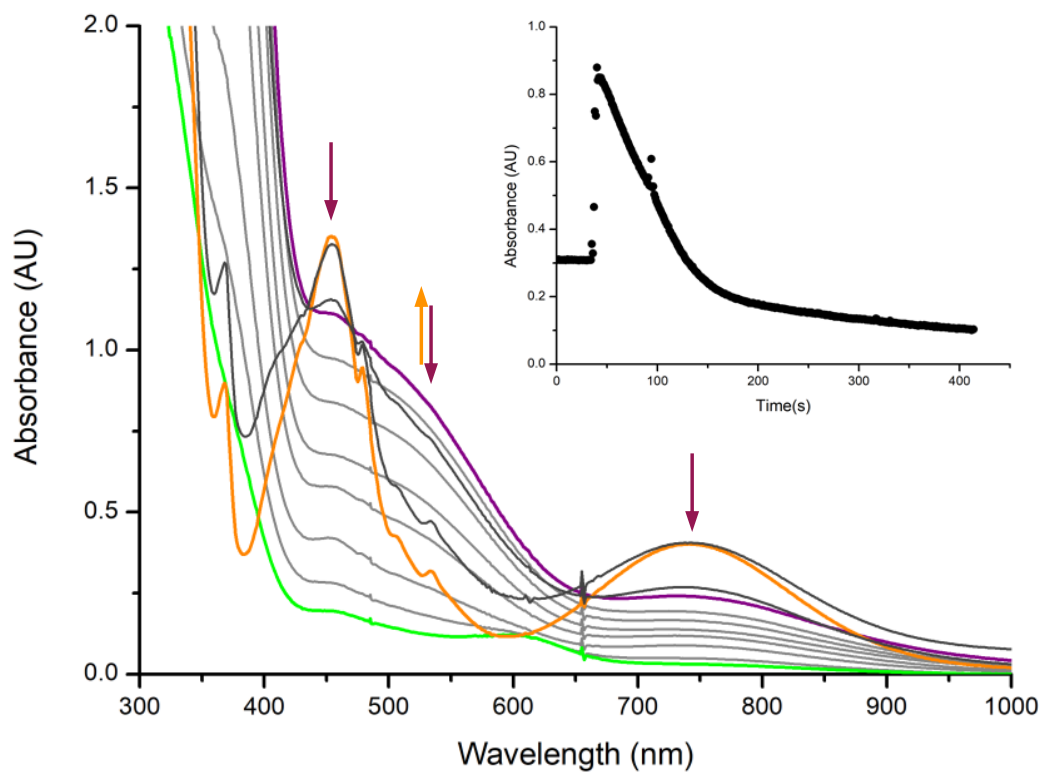

Figure S3. UV-vis spectral changes of $\left[\mathrm{Mn}^{\mathrm{IV}} \mathrm{BDP}{ }^{\mathrm{Br}} \mathrm{P}(\mathrm{OOH})\right]^{+}(\mathbf{1})(1.0 \mathrm{mM}$; purple trace) showing the natural decay of $\mathbf{1}$ in THF at $-80{ }^{\circ} \mathrm{C}$ within 2 mins. The inset shows time profile of the natural decay of 1 monitored at $530 \mathrm{~nm}$. 


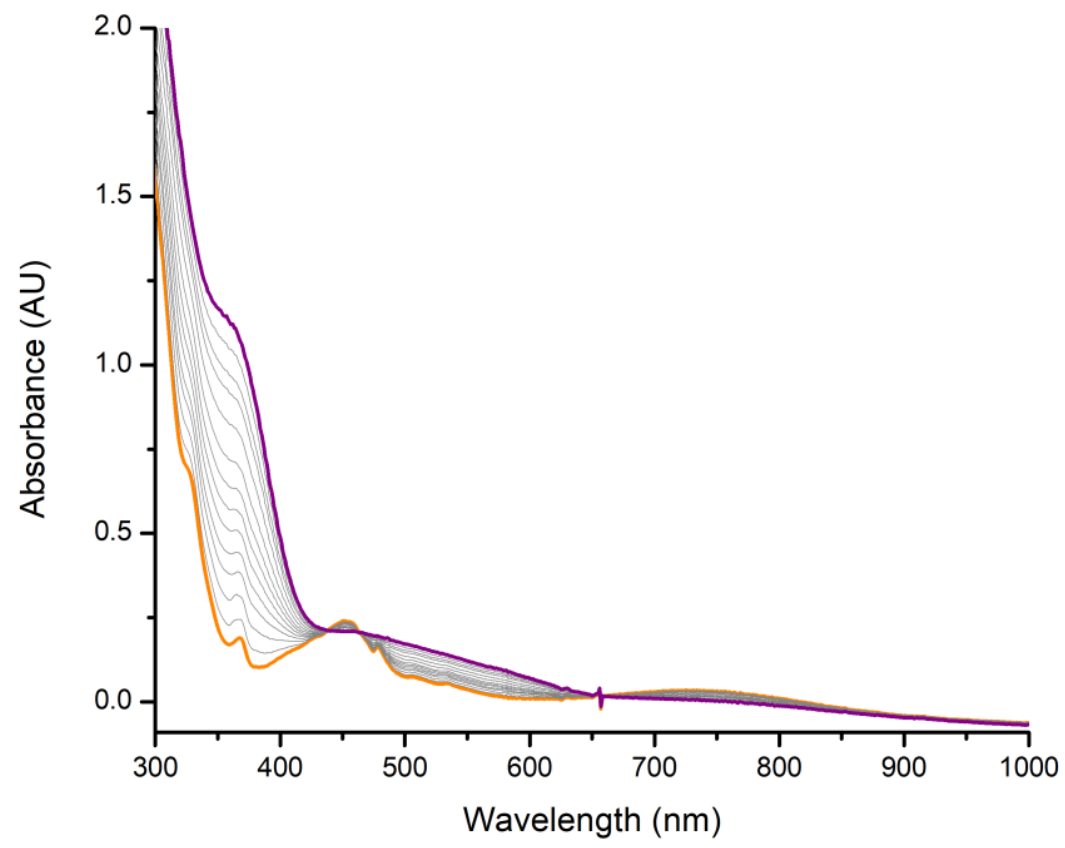

Figure S4. UV-vis spectral changes of the reaction of $\mathrm{Mn}^{\mathrm{III}}\left(\mathrm{BDP}^{\mathrm{Br}} \mathrm{P}\right)\left(\mathrm{O}_{2}{ }^{\circ}\right)(2)(0.2 \mathrm{mM}$, orange trace) with 1 equiv of TFA in MeTHF at $-120^{\circ} \mathrm{C}$ in 1 hour. The spectrum of 2 in MeTHF is identical to that in THF. 


\section{Equilibrium constant for the reaction of $\mathrm{Mn}\left(\mathrm{BDP}^{\mathrm{Br}} \mathrm{P}\right)\left(\mathrm{O}_{2}{ }^{\circ}\right)$ (2) with trifluoroacetic acid $\left(\mathrm{CF}_{3} \mathrm{COOH}\right)$}

Protonation of $\mathrm{Mn}\left(\mathrm{BDP}^{\mathrm{Br}} \mathrm{P}\right)\left(\mathrm{O}_{2}{ }^{\circ}\right)(2)$ by trifluoroacetic acid $\left(\mathrm{CF}_{3} \mathrm{COOH}\right)$ produced the $\mathrm{Mn}^{\mathrm{IV}}$-hydroperoxo complex, $\left[\mathrm{Mn}^{\mathrm{IV}}\left(\mathrm{BDP}^{\mathrm{Br}} \mathrm{P}\right)(\mathrm{OOH})\right]^{+}(\mathbf{1})$. The DFT calculations suggest that the anion, $\mathrm{CF}_{3} \mathrm{COO}^{-}$, does not attach to the cation of $\mathbf{1}$ as seen in Eq. 2 . The yield of 1 is about $91 \%$ obtained from the titration curve. The equilibrium constant $\left(K_{\text {eq }}\right)$ of the reaction of 2 with $\mathrm{CF}_{3} \mathrm{COOH}$ is around 102 calculated by Eq. 3 .

$$
\begin{gathered}
\mathrm{Mn}\left(\mathrm{BDP}^{\mathrm{Br}} \mathrm{P}\right)\left(\mathrm{O}_{2}{ }^{\circ}\right)+\mathrm{CF}_{3} \mathrm{COOH} \rightleftharpoons\left[\mathrm{Mn}^{\mathrm{IV}}\left(\mathrm{BDP}^{\mathrm{Br}} \mathrm{P}\right)(\mathrm{OOH})\right]\left(\mathrm{CF}_{3} \mathrm{COO}\right) \\
\boldsymbol{K}_{\mathbf{e q}}=\frac{\left[\mathbf{M n}^{\mathbf{I V}}\left(\mathbf{B D P}^{\mathrm{Br}} \mathbf{P}\right)(\mathbf{O O H})^{+}\right] \times\left[\mathbf{C F}_{\mathbf{3}} \mathbf{C O O}^{-}\right]}{\left[\mathbf{M n}^{\mathrm{III}}\left(\mathbf{B D P}^{\mathbf{B r}} \mathbf{P}\right)\left(\mathbf{0}_{\mathbf{2}}{ }^{\circ}\right] \times\left[\mathbf{C F}_{\mathbf{3}} \mathbf{C O O H}\right]\right.}
\end{gathered}
$$
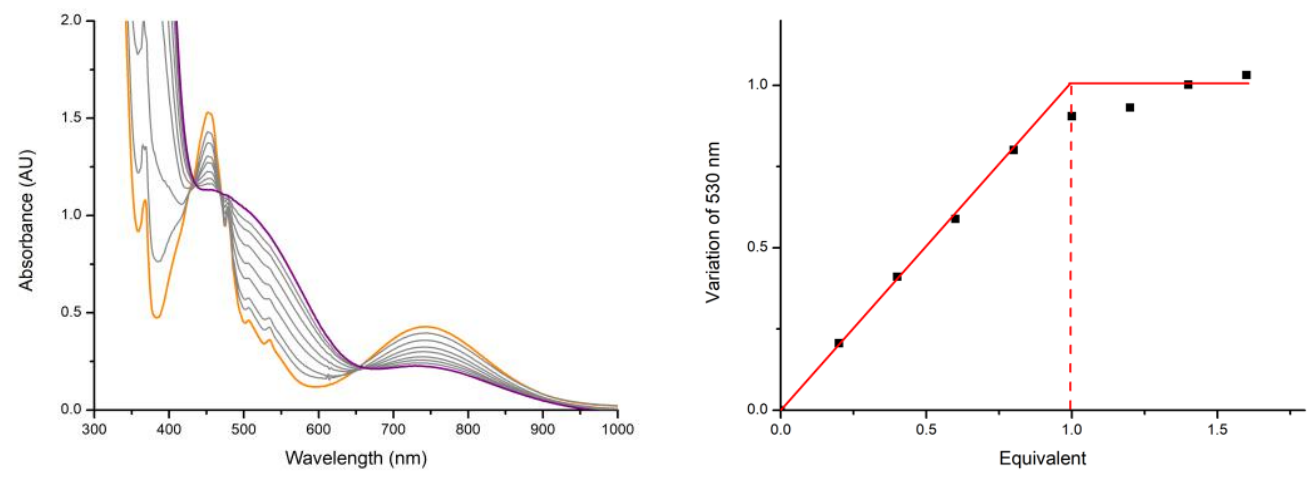

Figure S5. UV-vis spectral changes of the reaction of $2(1.0 \mathrm{mM}$, orange trace) with 1 equiv of TFA in MeTHF at $-120{ }^{\circ} \mathrm{C}$ (left). Titration curve of 2 with TFA. X-axis: the equivalent of TFA, Y-axis: the conversion ratio of the absorption peak at $530 \mathrm{~nm}$ (right). 


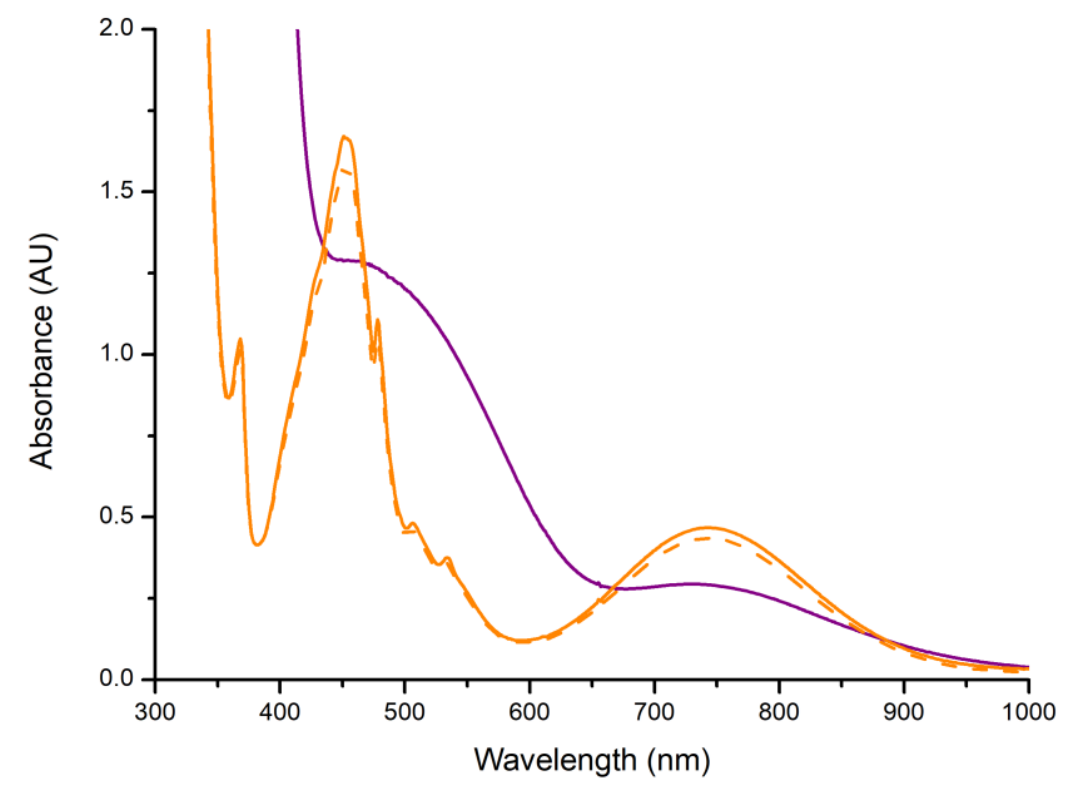

Figure S6. UV-vis spectra of $\mathrm{Mn}^{\mathrm{III}}\left(\mathrm{BDP}^{\mathrm{Br} P}\right)\left(\mathrm{O}_{2}{ }^{\circ}\right)(2)(1 \mathrm{mM}$, orange trace), the protonated product $\left[\mathrm{Mn}^{\mathrm{IV}} \mathrm{BDP}^{\mathrm{Br}} \mathrm{P}(\mathrm{OOH})\right]^{+}(\mathbf{1})(1 \mathrm{mM}$, purple trace), and the regenerated $2(1 \mathrm{mM}$; obtained from deprotonation of 1 by 1 equiv of DBU, orange dash trace) in MeTHF at $-120^{\circ} \mathrm{C}$.

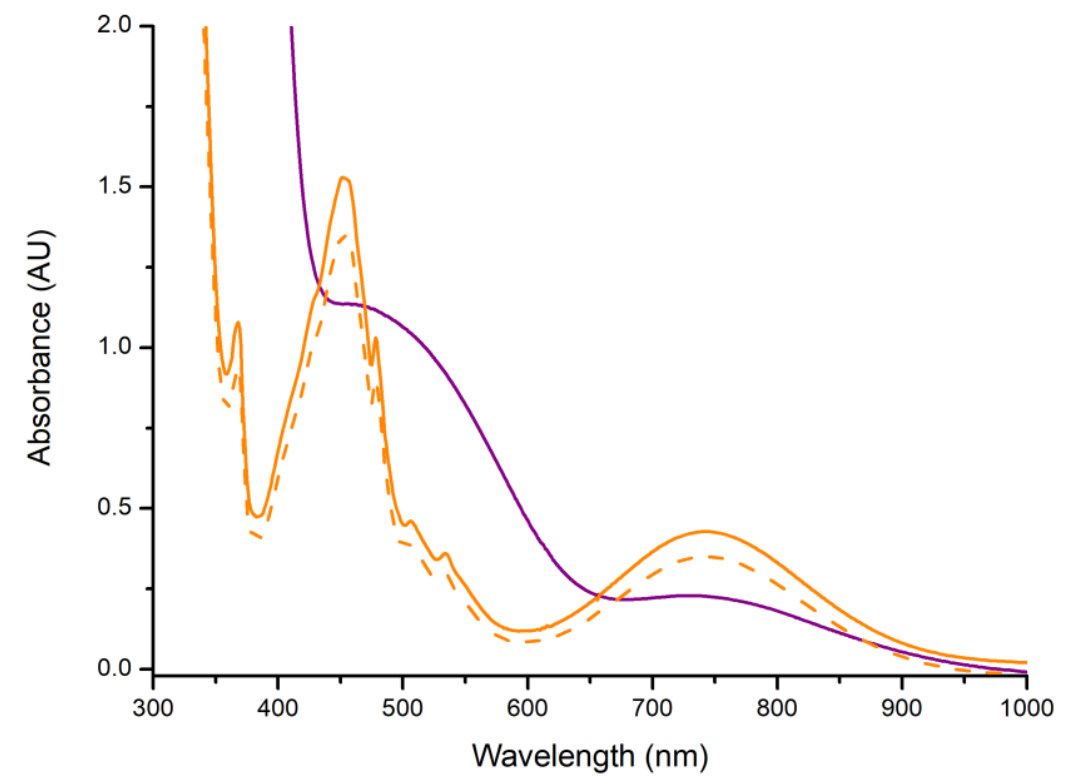

Figure S7. UV-vis spectra of $\mathrm{Mn}^{\mathrm{III}}\left(\mathrm{BDP}^{\mathrm{Br}} \mathrm{P}\right)\left(\mathrm{O}_{2}{ }^{\circ}\right)$ (2) (1 $\mathrm{mM}$, orange trace), $\left[\mathrm{Mn}^{\mathrm{IV}}\left(\mathrm{BDP}^{\mathrm{Br}} \mathrm{P}\right)(\mathrm{OOH})\right]^{+}(\mathbf{1})(1 \mathrm{mM}$; obtained from protonation of $\mathbf{2}$ by 1 equiv of TFA, purple trace), and regenerated $\mathrm{Mn}^{\mathrm{III}}\left(\mathrm{BDP}^{\mathrm{Br}} \mathrm{P}\right)\left(\mathrm{O}_{2}{ }^{\circ}\right)(2)(1 \mathrm{mM}$; obtained from deprotonation of 1 by 1 equiv of $\mathrm{NEt}_{3}$, orange dash trace) in MeTHF at $-120{ }^{\circ} \mathrm{C}$. 


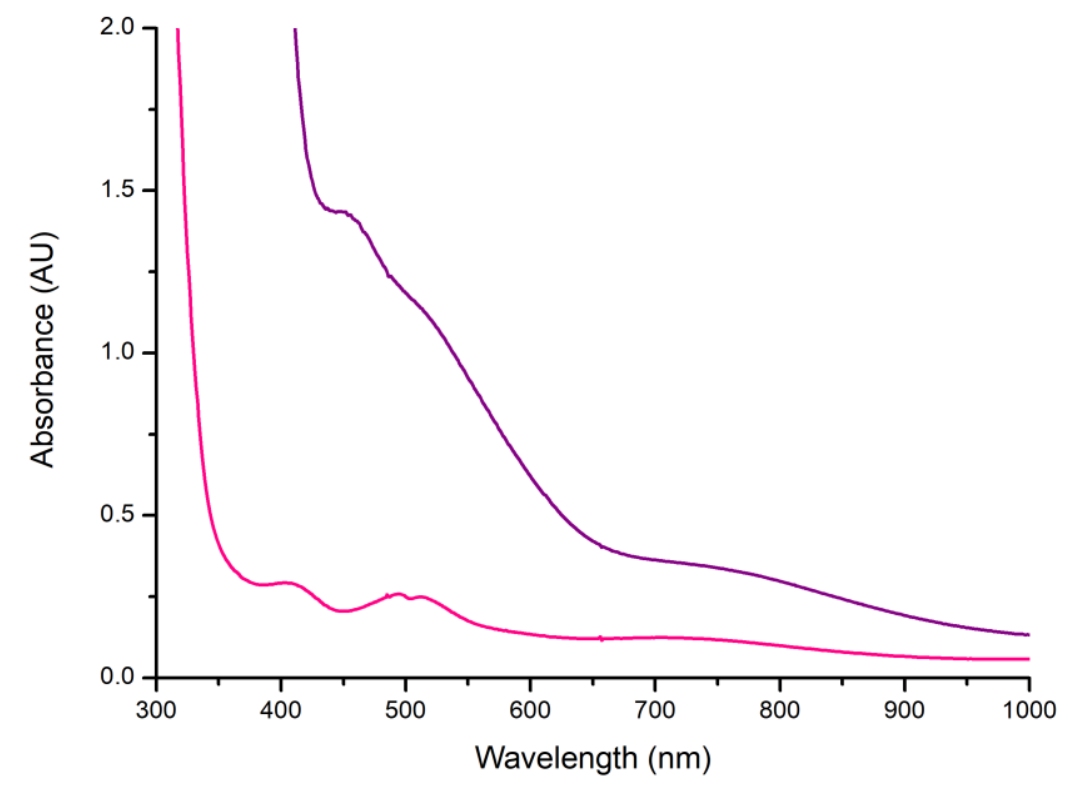

Figure S8. UV-vis spectra of $\mathrm{Mn}^{\mathrm{III}} \mathrm{BDP}{ }^{\mathrm{Br}} \mathrm{P}(\mathrm{OOH})(3)(1.0 \mathrm{mM}$, pink trace) and the resulting solution after adding 1 equiv of magic blue in $n-\mathrm{PrCN}$ at $-110^{\circ} \mathrm{C}$ (purple trace).

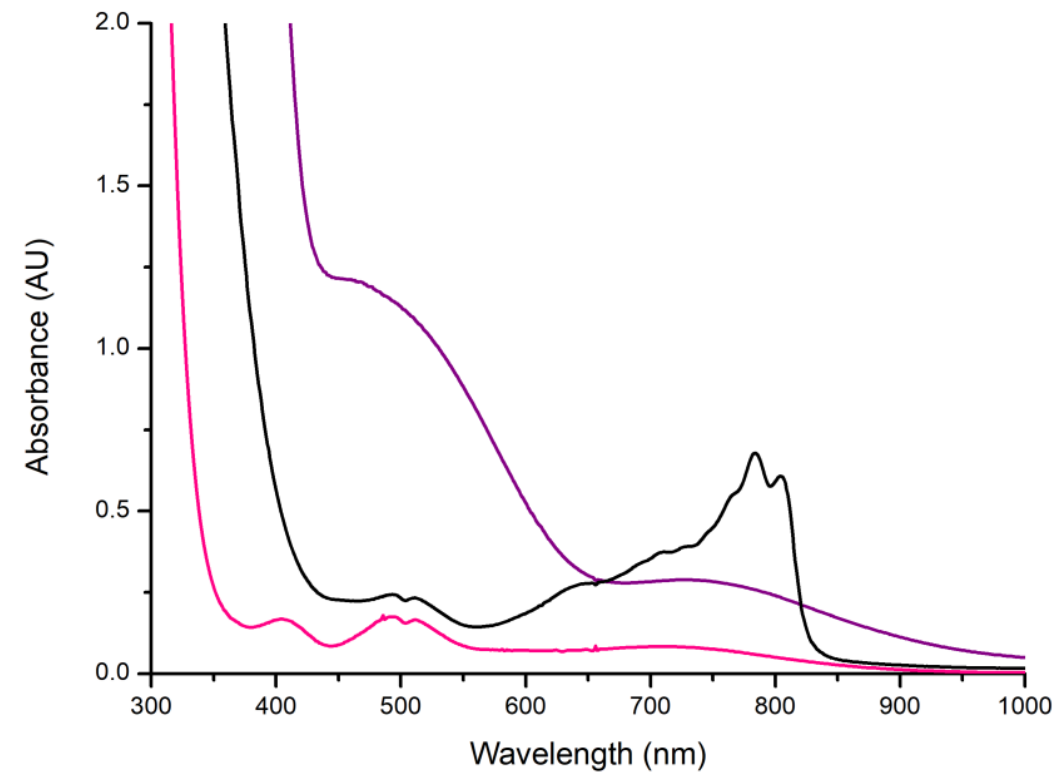

Figure S9. UV-vis spectra of $\left[\mathrm{Mn}^{\mathrm{IV}}\left(\mathrm{BDP}^{\mathrm{Br}} \mathrm{P}\right)(\mathrm{OOH})\right]^{+}$(1) $(1 \mathrm{mM}$, purple trace) and the reaction mixture of 1 with 1 equiv of $\mathrm{Fc}^{*}$ (black trace, $1 \mathrm{mM}$ ) in $\mathrm{MeTHF}$ at $-120{ }^{\circ} \mathrm{C}$ as well as $\mathrm{Mn}^{\mathrm{III}}\left(\mathrm{BDP}^{\mathrm{Br}} \mathrm{P}\right)(\mathrm{OOH})(3)(1 \mathrm{mM}$, pink trace $)$ at $-90^{\circ} \mathrm{C}$ in THF. 


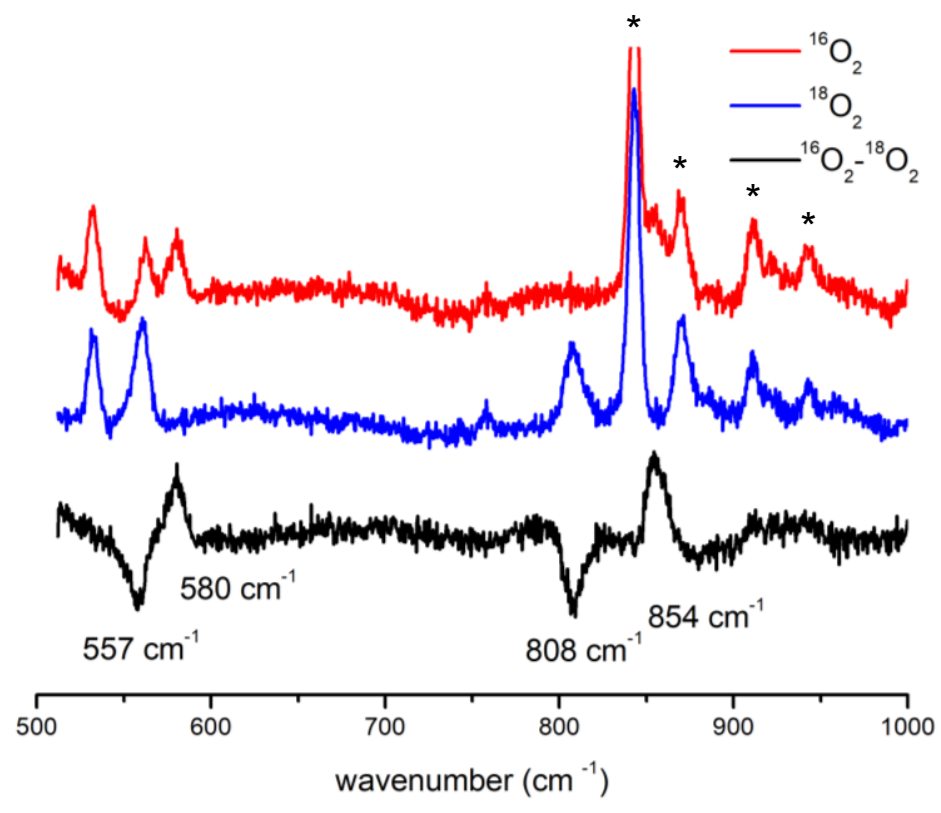

Figure S10. Resonance Raman spectra of the frozen $\left[\mathrm{Mn}^{\mathrm{IV}} \mathrm{BDP}^{\mathrm{Br}} \mathrm{P}(\mathrm{OOH})\right]^{+}(\mathbf{1})$ obtained from oxidation of $\mathrm{Mn}^{\mathrm{III}} \mathrm{BDP}{ }^{\mathrm{Br}} \mathrm{P}(\mathrm{OOH})(3)$ by magic blue at $-110{ }^{\circ} \mathrm{C}$ in $\mathrm{n}-\mathrm{PrCN}(10 \mathrm{mM}$, $\lambda_{\text {ex }} 594 \mathrm{~nm}, 20 \mathrm{~mW}, 77 \mathrm{~K}$; red line: $1{ }^{16} \mathrm{O}$, blue line: $1{ }^{18} \mathrm{O}$, black line: difference spectrum $\left.1-{ }^{16} \mathrm{O}-\mathbf{1 -}{ }^{18} \mathrm{O}\right)$. Asterisks denote solvent peaks. 


\section{EPR Experiments}

Temperature dependence of the X-band EPR spectrum of 1. Figure S11A shows magnetic sublevel energy diagrams for the opposite signs of the zfs parameter $D(S=3 / 2$, $B_{0} \| \mathrm{z}$ ), with red arrows denoting transition $\varepsilon$ for the X-band frequency. As the temperature is varied, changes in the EPR intensity of transition $\varepsilon$ depend on the sign of $D$. For $D>0$ (see Figure $\mathrm{S} 11 \mathrm{~A}$, top) the $M_{S} \approx \pm 3 / 2$ doublet has a higher energy than the $M_{S} \approx \pm 1 / 2$ doublet. In this case the population of the excited state doublet increases with the temperature, leading to an increase in the intensity $(I \times T)$ of transition $\varepsilon$. For $D<0$ the order of the $M_{S} \approx$ $\pm 3 / 2$ and $\pm 1 / 2$ doublets is inverted (Figure S11A, bottom), and the intensity of transition $\varepsilon$ decreases as the temperature is increased.

EPR spectra of 1 measured at $T=3.8 \mathrm{~K}$ (black solid curve) and $8 \mathrm{~K}$ (blue dotted curve) are shown in Figure S11B. To account for the Curie temperature dependence of magnetization (resulting in EPR intensity $I_{\mathrm{EPR}} \propto 1 / T$ ), the detected EPR intensity was multiplied by the corresponding temperature. The leftmost sharp EPR lines, which correspond to transition $\varepsilon$ (see main text for details), show higher intensity at $T=8 \mathrm{~K}$ compared to $3.8 \mathrm{~K}$. In Figure $\mathrm{S} 11 \mathrm{C}$, the $I \times T$ value of transition $\varepsilon$ is plotted as a function of $T$ in the range from 3.8 to $12 \mathrm{~K}$. The observed increase in the EPR intensity clearly demonstrates that $D>0$. The best fit (red solid line) was obtained for $D \approx 1 \mathrm{~cm}^{-1}$ by a leastsquares minimization procedure using the EasySpin toolbox. We note that a $D$ value in this range $\left(1 \mathrm{~cm}^{-1} \approx 1.4 \mathrm{~K}\right)$ is too small to be accurately determined by using an EPR set-up with the minimal available temperature of $3.8 \mathrm{~K}$. Thus, the result is treated as an estimation, while a more precise $D$ value is obtained from the Q-band EPR line shape simulations (see main text and below). 

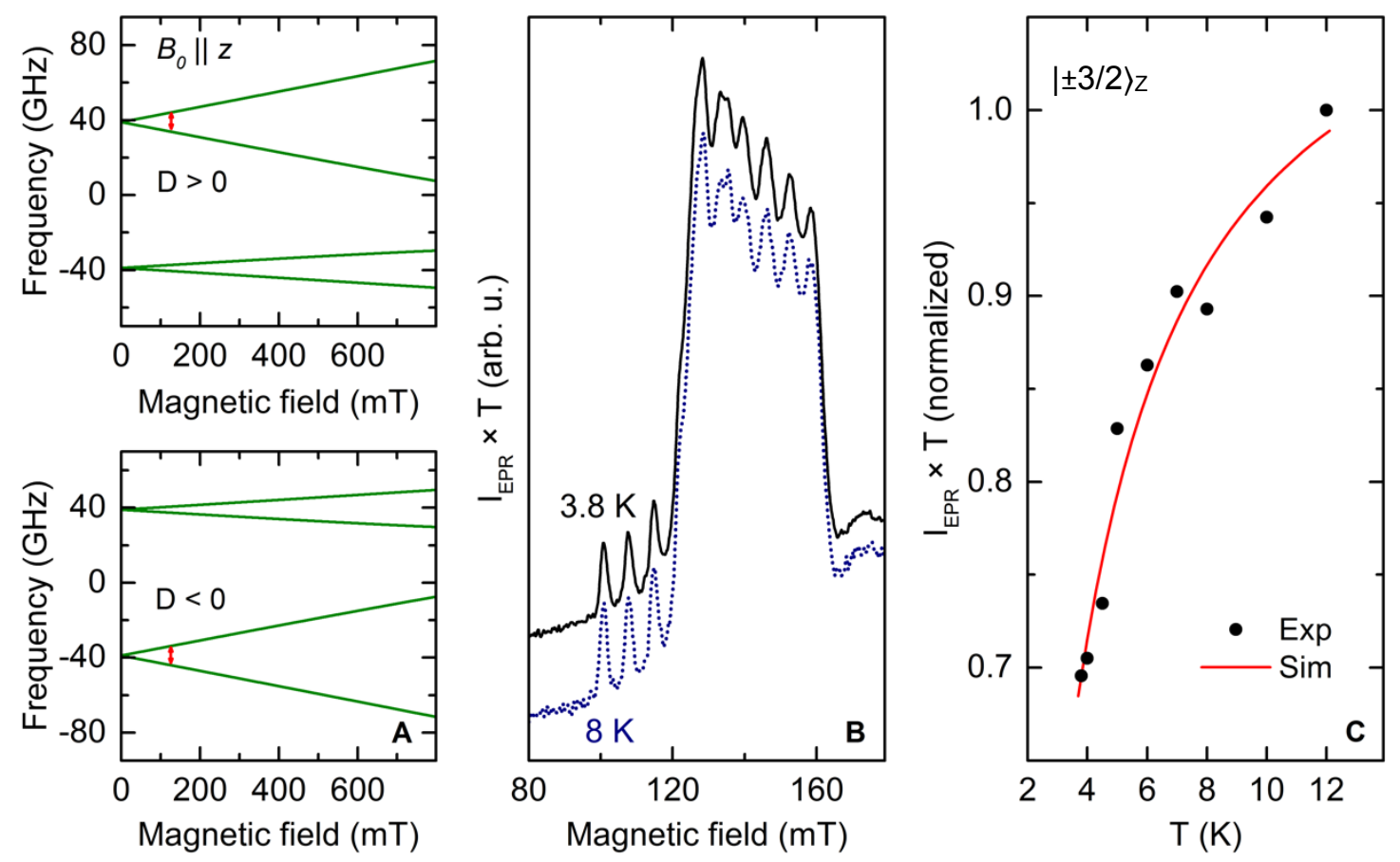

Figure S11. (A) Magnetic sublevel energy diagrams for a positive (top) and negative (bottom) $D$ value $\left(S=3 / 2,|D|=1.25 \mathrm{~cm}^{-1}, E / D=0.163\right)$; the $| \pm 3 / 2\rangle_{\mathrm{z}}(\varepsilon)$ transition is shown with red arrows for the X-band frequency. (B) CW X-band EPR spectra of 1 measured at $T=3.8 \mathrm{~K}$ (black solid trace) and $8 \mathrm{~K}$ (blue dotted trace); $f_{\mathrm{mw}}=9.65 \mathrm{GHz}, P_{\mathrm{mw}}=0.2 \mathrm{~mW}$. (C) Temperature dependence of the EPR intensity of transition $\varepsilon$ (multiplied by the corresponding temperature). The best fit (red solid line) was obtained for $D \approx 1 \mathrm{~cm}^{-1}$. 
Q-band EPR background correction. We measured more than twenty X-band EPR samples and always observed junk $\mathrm{Mn}^{2+}$ signal in the $g \approx 2$ region distinguished by the $M_{S}$ $=-1 / 2 \leftrightarrow+1 / 2 \mathrm{hf}$ sextet, for which Figure S12 shows an example. Its signal intensity was found to be batch-dependent and not correlated with the EPR intensity of 1 . Thus, this $\mathrm{Mn}^{2+}$ species is likely to be one of the decay products of $\mathbf{1}$ due to the intrinsic instability of $\mathbf{1}$. In line with this, we were not able to prepare a Q-band sample without a considerable amount of the decay products, because a Q-band sample tube is much smaller than an X-band sample tube, and it is much more difficult to transfer the sample into it. Therefore, EPR spectra of 1 recorded at Q-band show strong background peaks in the $\mathrm{g} \approx 2$ region (Figure S13), which include the free $\mathrm{Mn}^{2+}$ EPR signature superimposed on a broader feature. Additionally, an unassigned EPR signal is observed at the zero field. Q-band spectra of two samples shown in Figure S13 are normalized to the EPR intensity of $\mathbf{1}$. Sample \#2 shows much stronger $g \approx 2$ background features compared to Sample \#1, while the relative intensity of the zero-field feature is significantly lower.

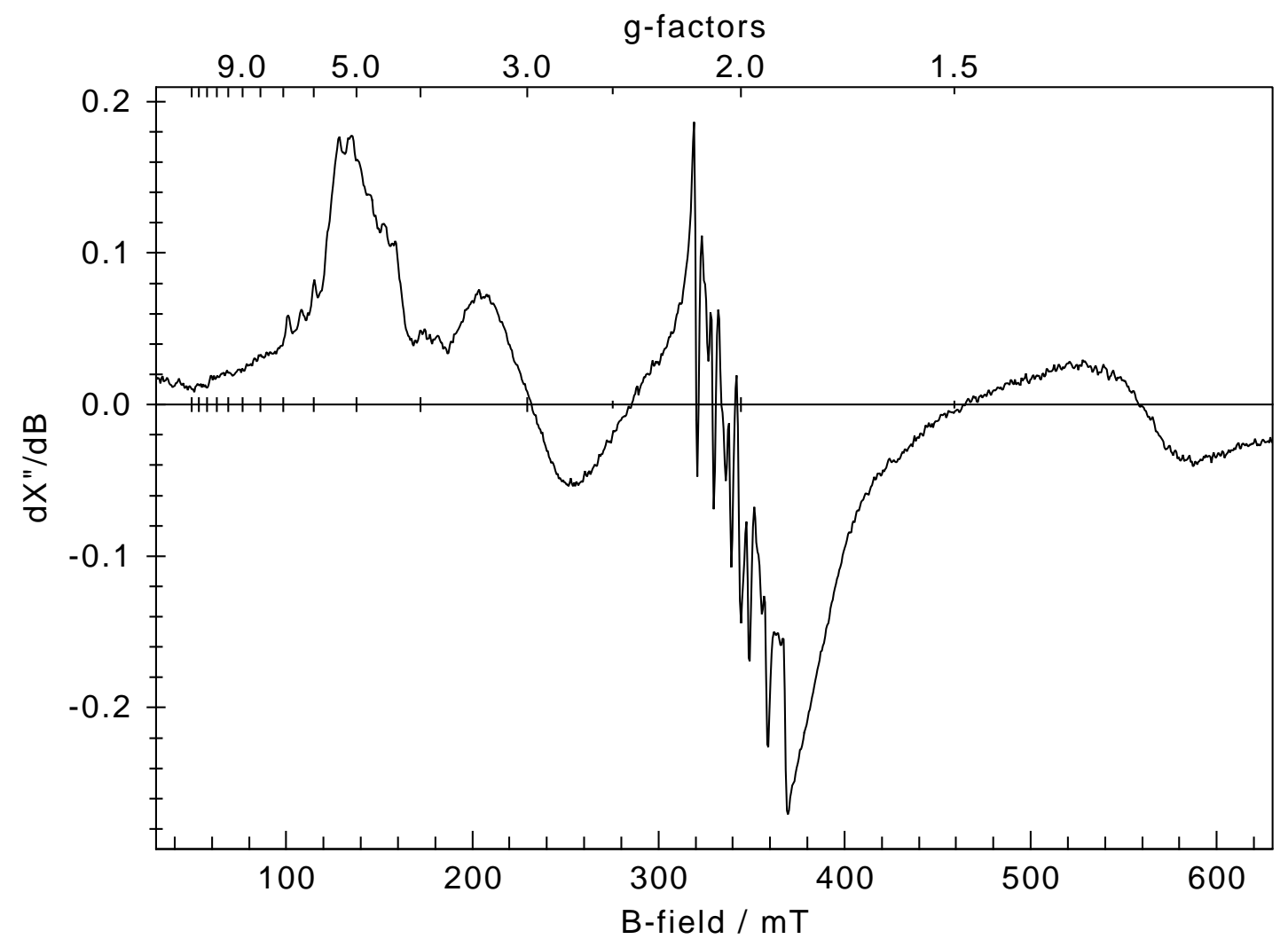

Figure S12. X-band EPR spectrum of 1 showing a strong junk $\mathrm{Mn}^{2+}$ signal. $T=10 \mathrm{~K}$, $f_{\mathrm{mw}}=9.637 \mathrm{GHz}$. 


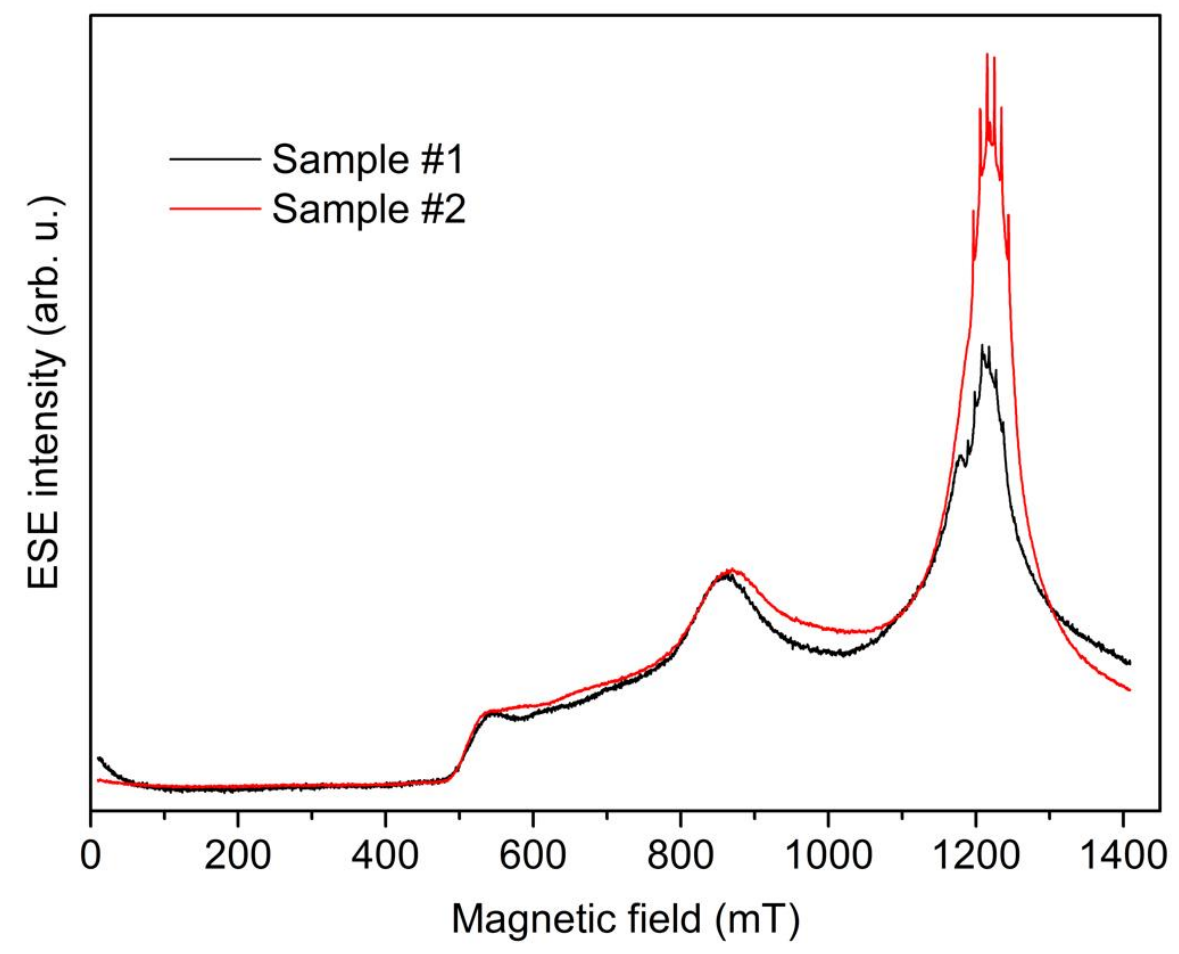

Figure S13. Pulse Q-band EPR spectra of two samples normalized to the EPR intensity of 1. $\mathrm{SRT}=50 \mathrm{~ns}, T=9 \mathrm{~K}, f_{\mathrm{mw}}=34.006 \mathrm{GHz}$. 
The broad background $\mathrm{g} \approx 2$ signal was isolated by increasing the inter-pulse delay from 280 to $680 \mathrm{~ns}$, which suppressed EPR species with shorter spin-spin relaxation times (Figure S14). Due to significant background intensity and potential ambiguities in the background subtraction, the spectral region between $B_{0}=1100$ and $1400 \mathrm{mT}$ (the magnet's limit) was not considered in the simulations (see Figure 3B of main text).

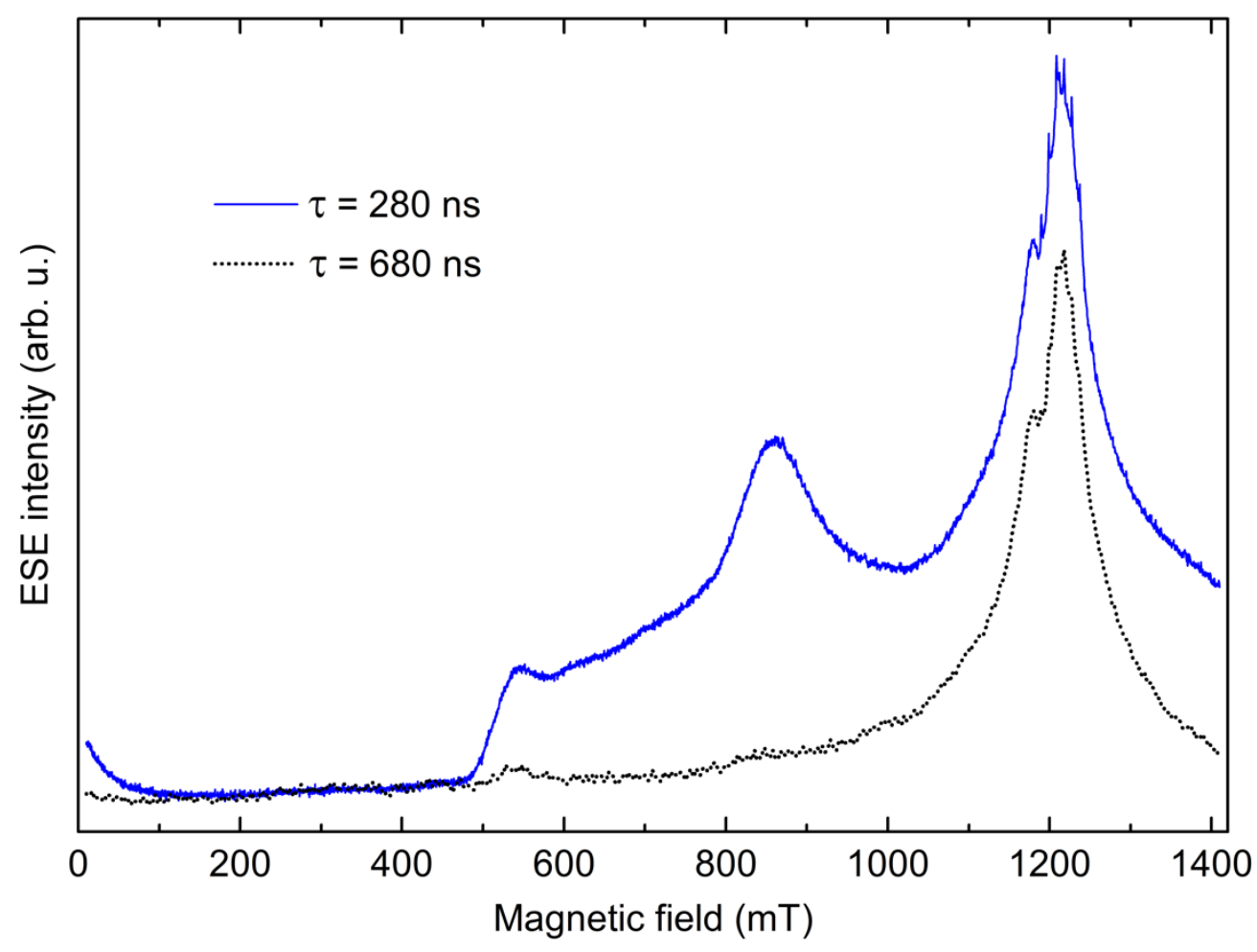

Figure S14. Pulse Q-band EPR spectra of 1 measured for an inter-pulse delay $\tau$ of 280 (blue solid line) and $680 \mathrm{~ns}$ (black dotted line). $T=9 \mathrm{~K}, f_{\mathrm{mw}}=34.006 \mathrm{GHz}$. 
Q-band EPR line shape simulations. The low-field edge of the Q-band spectrum $(\approx 500 \mathrm{mT})$ is defined by transition $\alpha^{\prime}$, while the prominent peak at $\approx 860 \mathrm{mT}$ originates from transition $\beta^{\prime}$. The precise position of $\beta$ ' depends on both the $D$ value (Figure S15, inset) and $E / D$ ratio, with $E / D=0.163(6)$ determined from the X-band data. Based on the spin-Hamiltonian simulations, this feature allowed us to estimate the higher limit of the axial zfs parameter as $D<1.5 \mathrm{~cm}^{-1}$. The best fit of the $\beta$ ' position was achieved for $D=1.25 \mathrm{~cm}^{-1}$ (red dotted line in Figure S15). We note that uncertainty in the $D$ value is directly affected by the uncertainty in the $E / D$ ratio, since the precise position of $\beta$ ' is determined by both parameters.

As discussed in the main text, the energy of a Q-band mw quantum is high enough to excite inter-doublet transitions $\xi$ for some orientations (blue dashed arrow in Figure 3E). In Figure S15 the corresponding spectral features are marked with asterisks. For higher $D$ values, and thus larger energy gap between the doublets, these EPR features shift rapidly to higher magnetic fields (see Figure S15). Based on our simulations, the fact that these features are not observed in the experiment suggests that $D \gtrsim 1.2 \mathrm{~cm}^{-1}$.

The precise value of the zfs parameter $D$ affects the high-field part of the Q-band spectrum (see Figure S15), which is not reachable on a resistive magnet in a standard Qband EPR set-up. The approximation of $D=1.25 \mathrm{~cm}^{-1}$ provided a satisfactory fit for both $\mathrm{X}$-band and available Q-band data.

No ${ }^{55} \mathrm{Mn}$ hf splitting was observed in the Q-band EPR spectrum, which is probably due to $D$ - and $g$-strain. ${ }^{17}$ 


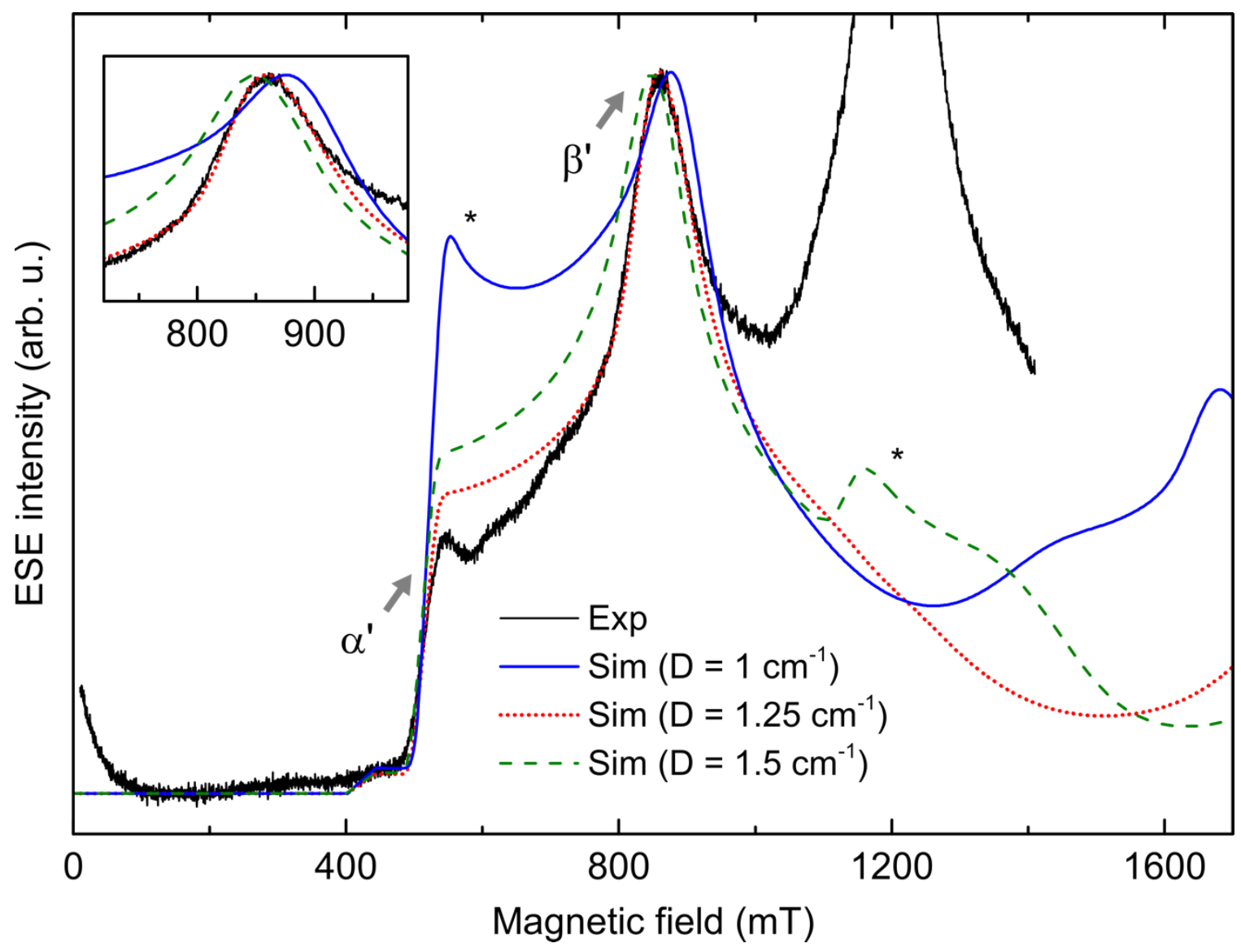

Figure S15. Simulated Q-band pulse EPR spectra of 1 calculated for several $D$ values: $1 \mathrm{~cm}^{-1}$ (blue solid line), $1.25 \mathrm{~cm}^{-1}$ (red dotted line) and $1.5 \mathrm{~cm}^{-1}$ (green dashed line). $E / D=0.163$ was assumed in all simulated spectra. The experimental spectrum (black solid line) is shown for comparison. Inset: expansion of the region between 720 and $980 \mathrm{mT}$. Asterisks mark spectral features originating from inter-doublet transitions. 
As shown in Figure S16, the molecular orbital analyses suggest that models $\mathbf{D}$ and $\mathbf{F}$, in fact, contain an intermediate spin $\mathrm{Mn}^{\mathrm{III}}$ center $\left(S_{\mathrm{Mn}}=1\right)$ that is ferromagnetically coupled a superoxo ligand, thereby yielding an overall quartet ground state. This electronicstructure description explains their highest $\mathrm{O}-\mathrm{O}$ stretching frequencies and axial zfsvalues $^{18}$ of all models and their highly anisotropic hf-tensor (Table S3). Models $\mathbf{E}$ and $\mathbf{G}$ indeed consist of a high-spin $\mathrm{Mn}^{\mathrm{IV}}$ center cleated by a side-on peroxo ligand. Protonation is expected to promote electron transfer from the $\mathrm{Mn}$ center to the $\mathrm{O}_{2}$ moiety due to enhanced electron accepting capability of the latter. Consequently, models $\mathbf{E}$ and $\mathbf{G}$ were predicted to have considerably higher $\mathrm{O}-\mathrm{O}$ stretching frequencies than $\mathbf{A}-\mathbf{C}$ having hydroperoxo ligands. More importantly, all of the calculated spectroscopic parameters of $\mathbf{A}$ are in reasonable agreement with the experimental values. In addition, $\mathbf{A}$ is the only model successfully replicating the sign of the axial zfs-value. Therefore, A should be the most practicable model for $\mathbf{1}$.

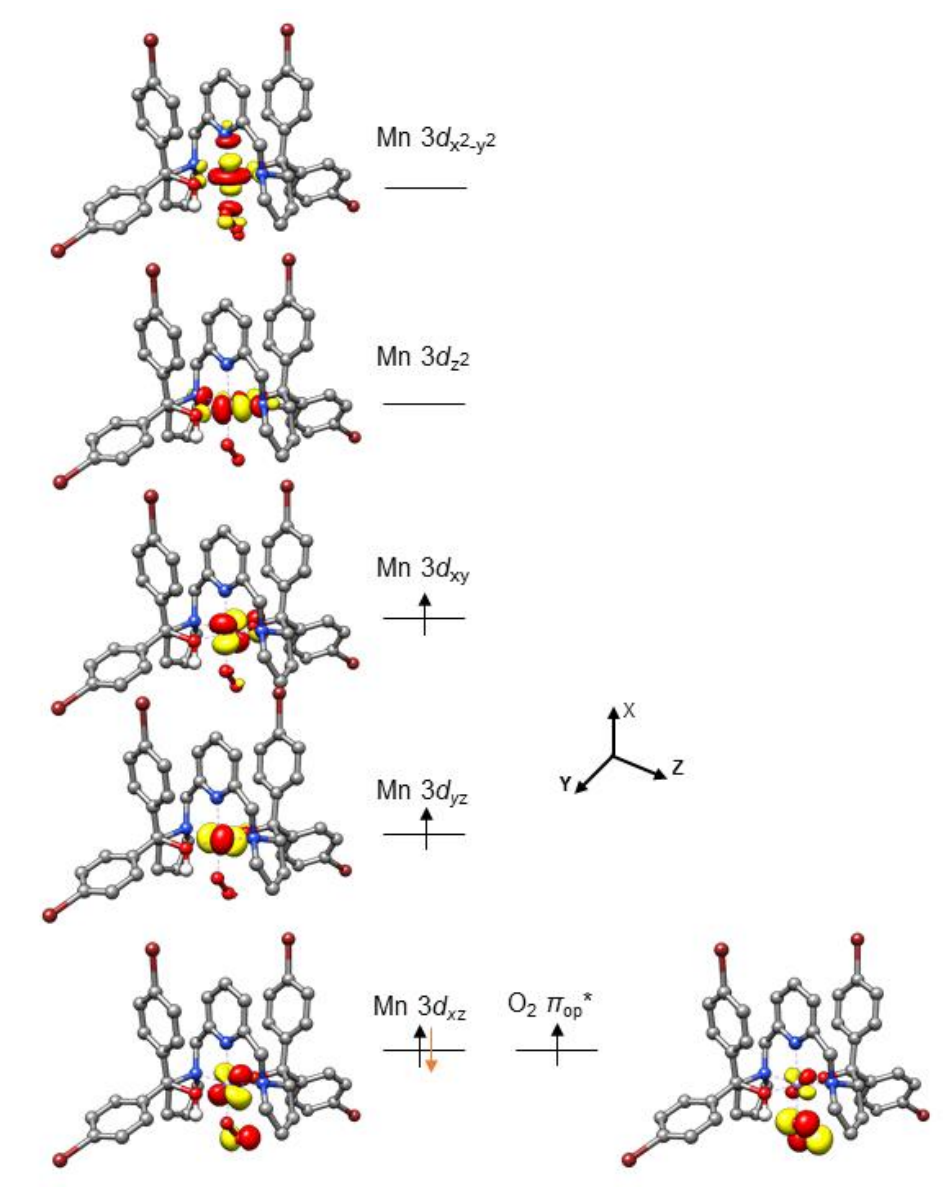

Figure S16. Computed model of $\mathbf{D}$ with the schematic molecular orbital diagram. 


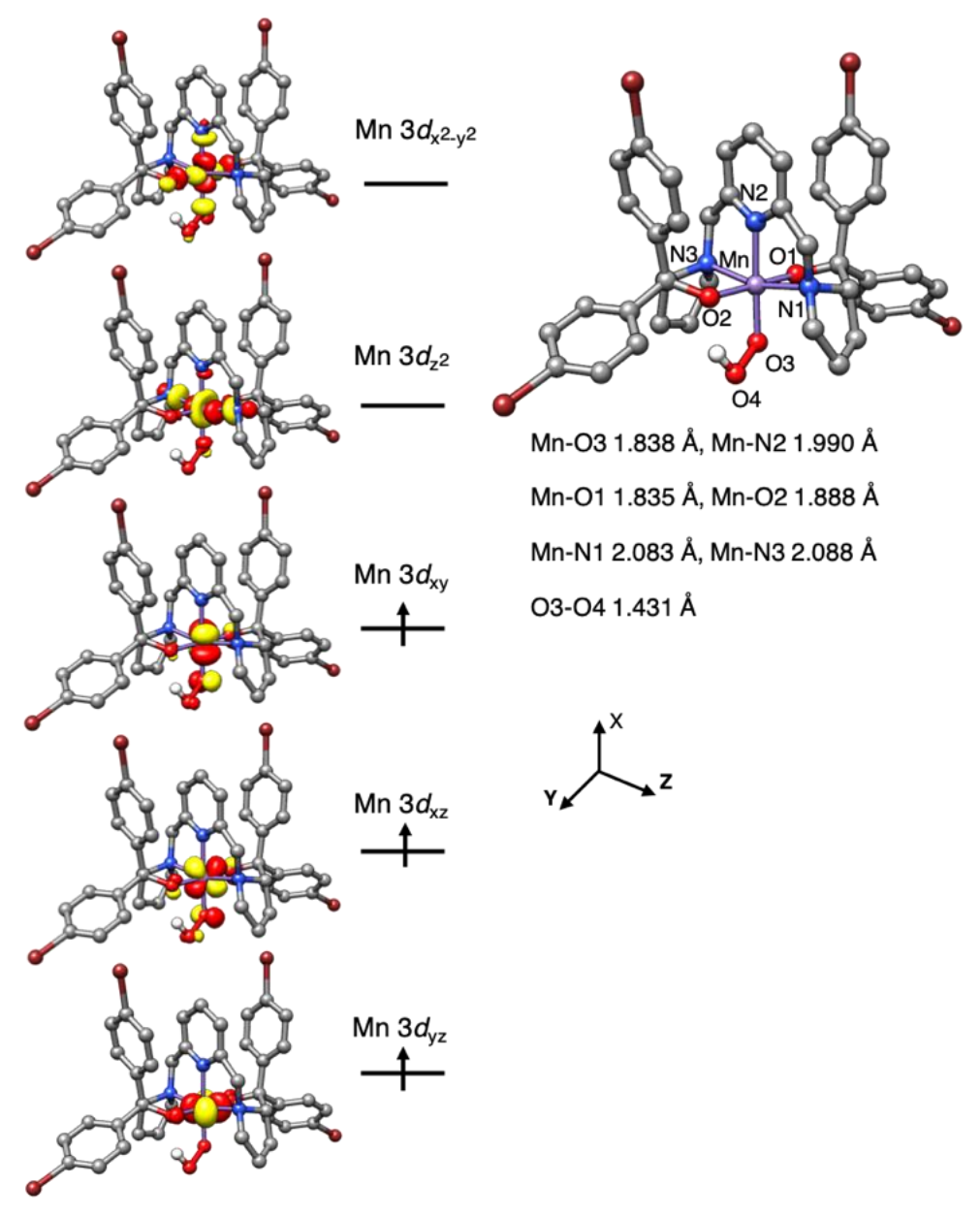

Figure S17. Computed structure of $\mathbf{A}$ with key geometric parameters and the schematic molecular orbital diagram. 


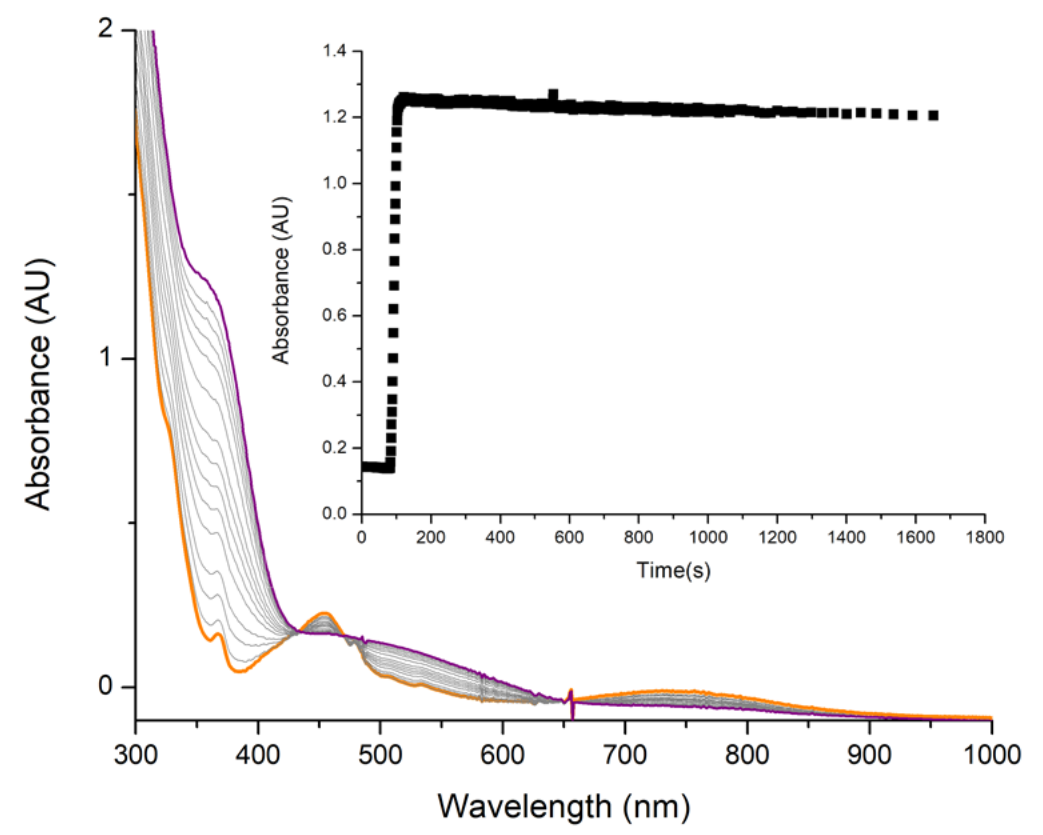

Figure S18. UV-vis spectral changes of the reaction of $\mathrm{Mn}^{\mathrm{III}}\left(\mathrm{BDP}^{\mathrm{Br}} \mathrm{P}\right)\left(\mathrm{O}_{2}{ }^{\circ}\right)(2)(0.2 \mathrm{mM}$, orange) with 1 equiv of $\mathrm{Sc}(\mathrm{OTf})_{3}$ in $\mathrm{THF}$ at $-80^{\circ} \mathrm{C}$. The inset shows time profile of the formation of 4 monitored at $360 \mathrm{~nm}$.

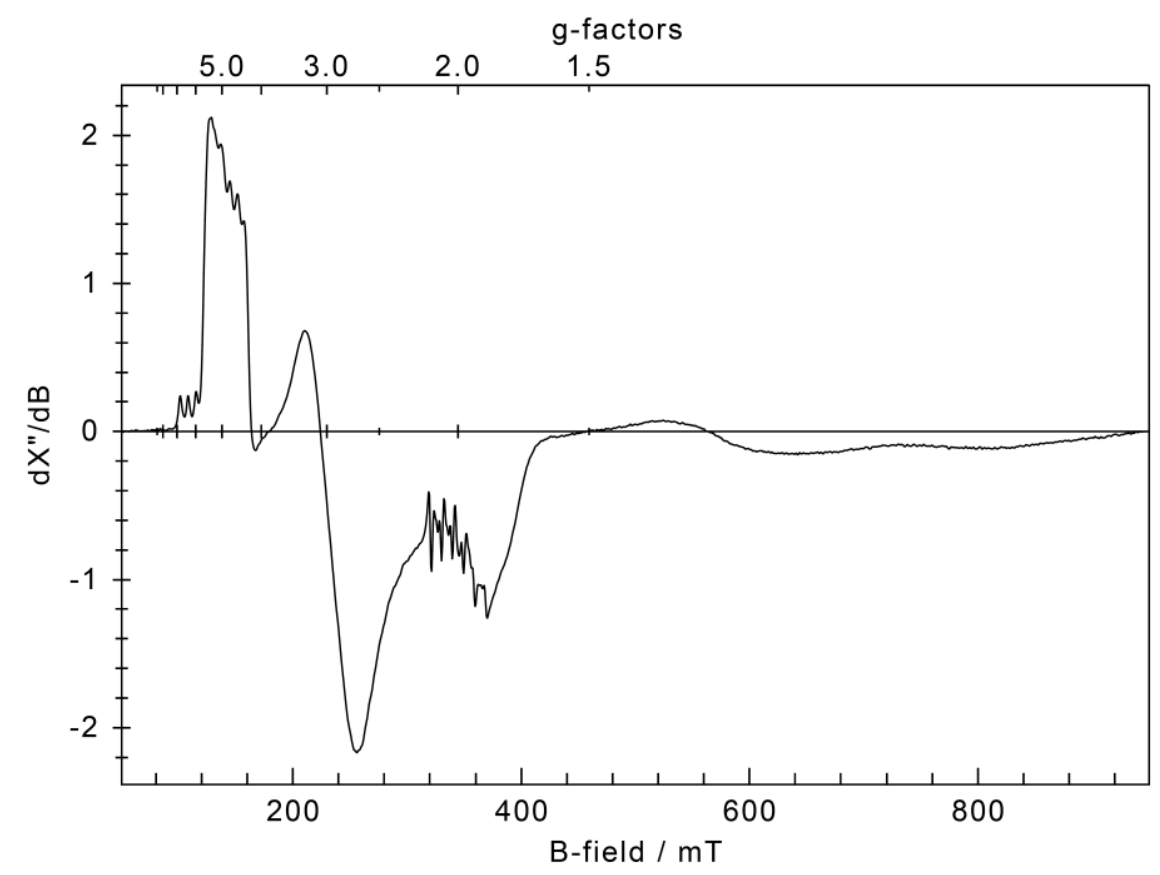

Figure S19. CW X-band EPR spectrum of $4(1.0 \mathrm{mM})$ measured at $T=4 \mathrm{~K} ; f_{\mathrm{mw}}=9.646$ $\mathrm{GHz}, P_{\mathrm{mw}}=2 \mathrm{~mW}$, Modulation $1.0 \mathrm{mT} / 100 \mathrm{kHz}$. 


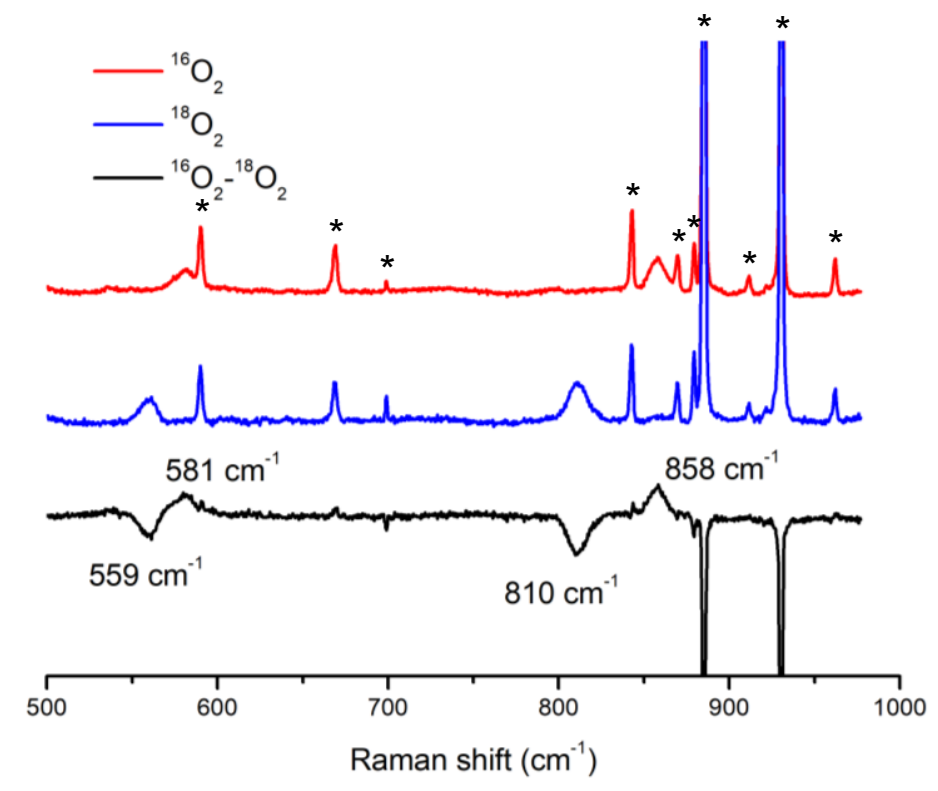

Figure S20. Resonance Raman spectra of the frozen $\left[\mathrm{Mn}^{\mathrm{IV}} \mathrm{BDP}^{\mathrm{Br}} \mathrm{P}(\mathrm{OO}) \mathrm{Sc}^{\mathrm{III}}\right]^{3+}(4)$ in $\mathrm{THF}$ at $-80{ }^{\circ} \mathrm{C}\left(10 \mathrm{mM}, \lambda_{\text {ex }} 594 \mathrm{~nm}, 20 \mathrm{~mW}, 77 \mathrm{~K}\right.$; red line: $1-{ }^{16} \mathrm{O}$, blue line: $1-{ }^{18} \mathrm{O}$, black line: difference spectrum $1-{ }^{16} \mathrm{O}-\mathbf{1}-{ }^{18} \mathrm{O}$ ). Asterisks denote solvent peaks. 
Table S1. O-O stretching frequencies of 1 and mononuclear $\mathrm{Mn}^{\mathrm{IV}}$-peroxo complexes.

\begin{tabular}{cccc}
\hline complex & $v\left({ }^{16} \mathrm{O}-{ }^{16} \mathrm{O}\right), \mathrm{cm}^{-1}$ & $v\left({ }^{18} \mathrm{O}-{ }^{18} \mathrm{O}\right), \mathrm{cm}^{-1}$ & reference \\
\hline $\mathbf{1}$ & 860 & 813 & This work \\
$\mathrm{Mn}^{\mathrm{IV}}(\mathrm{TPP})\left(\mathrm{O}_{2}\right)$ & 983 & 933 & 19 \\
{$[\mathrm{PPN}]\left[\mathrm{Mn}^{\mathrm{IV}}\left(\mathrm{O}_{2}\right)\left({ }^{\mathrm{TMS}} \mathrm{PS} 3\right)\right]$} & 903 & 861 & 20 \\
{$\left[\mathrm{Mn}^{\mathrm{IV}}(\mathrm{TAML})\left(\mathrm{O}_{2}\right)\right]^{2-}$} & 905 & 860 & 21 \\
\hline
\end{tabular}

$\mathrm{H}_{2} \mathrm{TPP}=5,10,15,20$-tetraphenylporphyrin

$[\mathrm{PPN}]^{+}=$bis(triphenylphosphine)iminium

${ }^{\mathrm{TMS}} \mathrm{PS} 3 \mathrm{H}_{3}=2,2^{\prime}, 2^{\prime \prime}$-trimercapto-3,3',3"-tris(trimethylsilyl)triphenylphosphine

TAML $=3,3,6,6,9,9$-hexametyl-2,5,7,10-tetraoxo3,5,6,7,9,10-hexahydro-2Hbenzo[e][1,4,7,10]tetraazacyclotridecine-1,4,8,11-tetraide 
Table S2. $D, E / D$ and $A$ values of $\mathrm{Mn}^{\mathrm{IV}}$ complexes.

\begin{tabular}{|c|c|c|c|c|}
\hline complex & $D\left(\mathrm{~cm}^{-1}\right)$ & $A(M H z)$ & $E / D$ & ref \\
\hline 1 & +1.25 & $-, 180,193$ & $0.163(6)$ & This work \\
\hline$\left[\mathrm{Mn}^{\mathrm{IV}}\left(\mathrm{L}^{\mathrm{Me}}\right)_{2}\right]$ & +1.6 & 202 & 0.17 & 22 \\
\hline$\left[\mathrm{Mn}^{\mathrm{IV}}\left(\mathrm{Me}_{3} \mathrm{TACN}\right)(\mathrm{OMe})_{3}\right]^{+}$ & $0.27(2)$ & $\mathrm{N}$ & 0 & 23 \\
\hline$\left[\mathrm{Mn}^{\mathrm{IV}}\left({ }^{\mathrm{t}} \mathrm{Bu}_{3} \text {-terpy }\right)_{2}\right]^{4+}$ & $1.33(6)$ & 188 & 0.27 & 24 \\
\hline$\left[\mathrm{Mn}^{\mathrm{IV}}(\mathrm{BQCN})(\mathrm{O})\left(\mathrm{OH}_{2}\right)\right]^{2+}$ & +2 & $\mathrm{~N}$ & 0 & 25 \\
\hline$\left[\mathrm{Mn}^{\mathrm{IV}} \mathrm{H}_{3}\right.$ buea $\left.(\mathrm{OH})\right]$ & $\begin{array}{l}+0.88(5) \\
+0.67(5)\end{array}$ & $\begin{array}{l}257,190,210 \\
252,210,210\end{array}$ & $\begin{array}{l}0.31(1) \\
0.17(1)\end{array}$ & 26 \\
\hline$\left[\mathrm{Mn}^{\mathrm{IV}}\left(\mathrm{O}_{4} \mathrm{~N}_{2}\right)\right]$ & 1.65 & $\mathrm{~N}$ & $\mathrm{~N}$ & 27 \\
\hline$\left[\mathrm{Mn}^{\mathrm{IV}} \mathrm{H}_{3} \text { buea }(\mathrm{O})\right]^{-}$ & $+2.5(2)$ & $165,188,244$ & $\begin{array}{c}0.259 \\
(0.024)\end{array}$ & 28 \\
\hline$\left[\mathrm{Mn}^{\mathrm{IV}}\left(\mathrm{L}^{\text {trans } \square \mathrm{N} 2 \mathrm{O} 4}\right)\right]$ & -0.997 & $\mathrm{~N}$ & 0.054 & 29 \\
\hline$\left[\mathrm{Mn}^{\mathrm{IV}}\left(\mathrm{L}^{\mathrm{O} 4 \mathrm{~S} 2}\right)\right]$ & +2.289 & $\mathrm{~N}$ & 0.141 & 29 \\
\hline$\left[\mathrm{Mn}^{\mathrm{IV}}(\mathrm{OH})_{2}\left(\mathrm{Me}_{2} \mathrm{EBC}\right)\right]^{2+}$ & $|0.75(25)|$ & 210 & 0.147 & 30 \\
\hline$\left[\mathrm{Mn}^{\mathrm{IV}}(\mathrm{O})(\mathrm{OH})\left(\mathrm{Me}_{2} \mathrm{EBC}\right)\right]^{+}$ & +1.0 & $220,204,210$ & 0.223 & 30 \\
\hline$\left[\mathrm{Mn}^{\mathrm{IV}} \mathrm{H}_{2} \operatorname{pout}(\mathrm{OH})\right]$ & $\begin{array}{l}+0.8(70 \%) \\
+0.7(30 \%)\end{array}$ & $\begin{array}{l}152,198,183 \\
224,188,201\end{array}$ & $\begin{array}{l}0.33 \\
0.17\end{array}$ & 31 \\
\hline
\end{tabular}

$\mathrm{H}_{2} \mathrm{~L}^{\mathrm{Me}}=$ methylamino-N,N-bis(2-methylene-4,6-dimethylphenol)

$\mathrm{BQCN}=\mathrm{N}, \mathrm{N}^{\prime}$-Dimethyl-N,N'-bis(8-quinolyl)cyclohexane-diamine

$\mathrm{Me}_{3} \mathrm{TACN}=1,4,7$-Trimethyl-1,4,7-triazacyclononane

${ }^{t} \mathrm{Bu}_{3}$-terpy $=4,4^{\prime}, 4^{\prime \prime}$-tritert-butyl-2,2':6',2"-terpyridine

$\left[\mathrm{H}_{3} \text { buea }\right]^{3-}=$ tris $\left[\left(\mathrm{N}^{\prime}\right.\right.$-tertbutylureaylato $)-\mathrm{N}$-ethylene $]$ aminato

$\mathrm{O}_{4} \mathrm{~N}_{2}=$ the tetra-anion of $\mathrm{N}, \mathrm{N}^{\prime}$-bis(2-hydroxyethyl)-N,N'-bis(3,5-di-tert-butyl-2hydroxybenzyl)ethylenediamine

$\mathrm{L}^{\text {trans } \square \mathrm{N} 2 \mathrm{O} 4}=\operatorname{bis}(2-\{[1,1$-bis(hydroxymethyl)-2-oxidoethyl $]$ iminomethyl $\}$-6-methoxyphenolato)

$\mathrm{L}^{\mathrm{O} 4 \mathrm{~S} 2}=$ bis[2,2'-thiobis(4,6-di-tert-butylphenolate)]

$\mathrm{Me}_{2} \mathrm{EBC}=4,11$-dimethyl-1,4,8,11-tetraazabicyclo[6.6.2]hexadecane

$\left[\mathrm{H}_{2} \text { pout }\right]^{3-}=\operatorname{bis}\left[\left(\mathrm{N}^{\prime}\right.\right.$-tertbutylureaylato)-N-ethylene $][($ diphenylphoshino $)-\mathrm{N}$-ethylene $]$ aminato 
Table S3. Computed Spectroscopic Parameters for Various Models of 1.

\begin{tabular}{cccccccc}
\hline & $\mathrm{O}-\mathrm{O}(\AA)$ & $\mathrm{Mn}-\mathrm{O}(\AA)$ & $\begin{array}{c}\mathrm{v}_{\mathrm{O}-\mathrm{O}} \\
\left(\mathrm{cm}^{-1}\right)\end{array}$ & $\begin{array}{c}\mathrm{v}_{\mathrm{Mn}-\mathrm{O}} \\
\left(\mathrm{cm}^{-1}\right)\end{array}$ & $\begin{array}{c}D \\
\left(\mathrm{~cm}^{-1}\right)\end{array}$ & $E / D$ & $\begin{array}{c}55 \mathrm{Mnh} \text { hftensor } \\
(\mathrm{MHz})\end{array}$ \\
\hline A & 1.438 & $1.852,2.815$ & 841 & 554 & +2.8 & 0.22 & $-151,-179,-183$ \\
B & 1.455 & $1.854,2.824$ & 872 & 567 & -2.1 & 0.18 & $-157,-180,-184$ \\
C & 1.438 & $1.831,2.829$ & 882 & 529 & -4.1 & 0.26 & $-166,-189,-202$ \\
D & 1.353 & $1.848,2.852$ & 1035 & 491 & +17.9 & 0.10 & $-60,-171,-201$ \\
E & 1.413 & $1.848,1.864$ & 967 & 558 & +3.8 & 0.32 & $-139,-179,-202$ \\
F & 1.371 & $1.849,2.844$ & 997 & 518 & +14.2 & 0.06 & $-81,-182,-188$ \\
G & 1.411 & $1.855,1.880$ & 969 & 540 & +3.0 & 0.24 & $-155,-198,-202$ \\
\hline
\end{tabular}




\section{Reference}

(1) Lin, Y. H.; Cramer, H. H.; van Gastel, M.; Tsai, Y. H.; Chu, C. Y.; Kuo, T. S.; Lee, I. R.; Ye, S.; Bill, E.; Lee, W. Z. Mononuclear Manganese(III) Superoxo Complexes: Synthesis, Characterization, and Reactivity. Inorg. Chem. 2019, 58, 9756-9765.

(2) Reijerse, E.; Lendzian, F.; Isaacson, R.; Lubitz, W. A tunable general purpose Q-band resonator for $\mathrm{CW}$ and pulse EPR/ENDOR experiments with large sample access and optical excitation. J. Magn. Reson. 2012, 214, 237-243.

(3) Stoll, S.; Schweiger, A. EasySpin, a comprehensive software package for spectral simulation and analysis in EPR. J. Magn. Reson. 2006, 178, 42-55.

(4) (a) Neese, F. The ORCA program system. WIREs Comput. Mol. Sci. 2012, 2, 73-78; (b) Neese, F. Software update: the ORCA program system, version 4.0. WIREs Comput. Mol. Sci 2018, 8, e1327.

(5) (a) Becke, A. D. Density-functional exchange-energy approximation with correct asymptotic behavior. Phys. Rev. A 1988, 38, 3098-3100; (b) Perdew, J. P. Erratum: Densityfunctional approximation for the correlation energy of the inhomogeneous electron gas. Phys. Rev. B 1986, 34, 7406-7406; (c) Perdew, J. P. Density-functional approximation for the correlation energy of the inhomogeneous electron gas. Phys. Rev. B 1986, 33, 88228824.

(6) Weigend, F.; Ahlrichs, R. Balanced basis sets of split valence, triple zeta valence and quadruple zeta valence quality for $\mathrm{H}$ to $\mathrm{Rn}$ : Design and assessment of accuracy. Phys. Chem. Chem. Phys. 2005, 7, 3297-3305.

(7) Weigend, F. Accurate Coulomb-fitting basis sets for H to Rn. Phys. Chem. Chem. Phys. 2006, 8, 1057-1065.

(8) Eichkorn, K.; Treutler, O.; Öhm, H.; Häser, M.; Ahlrichs, R. Auxiliary basis sets to approximate Coulomb potentials (Chem. Phys. Letters 240 (1995) 283-290). Chem. Phys. Lett. 1995, 242, 652-660.

(9) (a) Becke, A. D. Density $\square$ functional thermochemistry. III. The role of exact exchange. J. Chem. Phys. 1993, 98, 5648-5652; (b) Lee, C.; Yang, W.; Parr, R. G. Development of the Colle-Salvetti correlation-energy formula into a functional of the electron density. Phys. Rev. B 1988, 37, 785-789.

(10) Neese, F. Prediction and interpretation of the 57Fe isomer shift in Mössbauer spectra by density functional theory. Inorg. Chim. Acta 2002, 337, 181-192.

(11) (a) Sinnecker, S.; Neese, F.; Noodleman, L.; Lubitz, W. Calculating the Electron Paramagnetic Resonance Parameters of Exchange Coupled Transition Metal Complexes Using Broken Symmetry Density Functional Theory: Application to a MnIII/MnIV Model Compound. J. Am. Chem. Soc. 2004, 126, 2613-2622; (b) Orio, M.; Pantazis, D. A.; Petrenko, T.; Neese, F. Magnetic and Spectroscopic Properties of Mixed Valence Manganese(III,IV) Dimers: A Systematic Study Using Broken Symmetry Density Functional Theory. Inorg. Chem. 2009, 48, 7251-7260.

(12) Neese, F. Metal and ligand hyperfine couplings in transition metal complexes: The effect of spin-orbit coupling as studied by coupled perturbed Kohn-Sham theory. J. Chem. Phys. 2003, 118, 3939-3948.

(13) Bencini, A.; Gatteschi, D.: EPR of Exchange Coupled Systems; Springer-Verlag: Berlin, 1990.

(14) Neese, F. Calculation of the zero-field splitting tensor on the basis of hybrid density functional and Hartree-Fock theory. J. Chem. Phys. 2007, 127, 164112. 
(15) The density matrix in many-electron quantum mechanics II. Separation of space and spin variables; spin coupling problems. Proc. R. Soc. London 1961, 259, 554.

(16) Sinnecker, S.; Neese, F. Spin-Spin Contributions to the Zero-Field Splitting Tensor in Organic Triplets, Carbenes and Biradicals-A Density Functional and Ab Initio Study. $J$. Phys. Chem. A 2006, 110, 12267-12275.

(17) (a) Bennet, B. EPR of Cobalt-Susbstituted Zinc Enzymes. Hanson, G.; Berliner, L. (eds.), Biological Magnetic Resonance, 29, 345-370; (b) Wang, D. M.; Pilbrow, J. R. Symmetry relationships for the four energy levels and the angular property of the EPR spectra for a spin-3/2 system. J. Magn. Reson. 1988, 77, 411-423.

(18) Forshaw, A. P.; Smith, J. M.; Ozarowski, A.; Krzystek, J.; Smirnov, D.; Zvyagin, S. A.; Harris, T. D.; Karunadasa, H. I.; Zadrozny, J. M.; Schnegg, A.; Holldack, K.; Jackson, T. A.; Alamiri, A.; Barnes, D. M.; Telser, J. Low-Spin Hexacoordinate Mn(III): Synthesis and Spectroscopic Investigation of Homoleptic Tris(pyrazolyl)borate and Tris(carbene)borate Complexes. Inorg. Chem. 2013, 52, 144-159.

(19) Urban, M. W.; Nakamoto, K.; Basolo, F. Infrared spectra of molecular oxygen adducts of (tetraphenylporphyrinato)manganese(II) in argon matrixes. Inorg. Chem. 1982, 21, 3406-3408.

(20) Lee, C. M.; Chuo, C. H.; Chen, C. H.; Hu, C. C.; Chiang, M. H.; Tseng, Y. J.; Hu, C. H.; Lee, G. H. Structural and Spectroscopic Characterization of a Monomeric Side-On Manganese(IV) Peroxo Complex. Angew. Chem. Int. Ed. 2012, 51, $5427-5430$.

(21) Hong, S.; Sutherlin, K. D.; Park, J.; Kwon, E.; Siegler, M. A.; Solomon, E. I.; Nam, W. Crystallographic and Spectroscopic Characterization and Reactivities of a Mononuclear Non-Haem Iron(III)-Superoxo Complex. Nat. Commun. 2014, 5, 5440-5547.

(22) Weyhermüller, T.; Paine, T. K.; Bothe, E.; Bill, E.; Chaudhuri, P. Complexes of an Aminebis(phenolate) [O,N,O] Donor Ligand and EPR Studies of Isoelectronic, Isostructural $\mathrm{Cr}(\mathrm{III})$ and $\mathrm{Mn}(\mathrm{IV})$ Complexes. Inorg. Chim. Acta 2002, 337, 344-356.

(23) Duboc, C.; Collomb, M.-N. Multifrequency High-Field EPR Investigation of a Mononuclear Manganese(iv) Complex. Chem. Commun. 2009, 2715-2717.

(24) Romain, S.; Baffert, C.; Duboc, C.; Leprêtre, J.-C.; Deronzier, A.; Collomb, M.-N. Mononuclear $\mathrm{Mn}^{\mathrm{III}}$ and $\mathrm{Mn}^{\mathrm{IV}}$ Bis-terpyridine Complexes: Electrochemical Formation and Spectroscopic Characterizations. Inorg. Chem. 2009, 48, 3125-3131.

(25) Sawant, S. C.; Wu, X.; Cho, J.; Cho, K.-B.; Kim, S. H.; Seo, M. S.; Lee, Y.-M.; Kubo, M.; Ogura, T.; Shaik, S.; Nam, W. Water as an Oxygen Source: Synthesis, Characterization, and Reactivity Studies of a Mononuclear Nonheme Manganese(IV) Oxo complex. Angew. Chem. Int. Ed. 2010, 49, 8190-8194.

(26) Gupta, R.; Taguchi, T.; Borovik, A. S.; Hendrich, M. P. Characterization of Monomeric $\mathrm{Mn}^{\mathrm{II} / \mathrm{II} / \mathrm{IV}}$-Hydroxo Complexes from X- and Q-Band Dual Mode Electron Paramagnetic Resonance (EPR) Spectroscopy. Inorg. Chem. 2013, 52, 12568-12575.

(27) Dolai, M.; Amjad, A.; Debnath, M.; Tol, J. v.; Barco, E. d.; Ali, M. Water-Stable Manganese(IV) Complex of a N2O4-Donor Non-Schiff-Base Ligand: Synthesis, Structure, and Multifrequency High-Field Electron Paramagnetic Resonance Studies. Inorg. Chem. 2014, 53, 5423-5428.

(28) Gupta, R.; Taguchi, T.; Lassalle-Kaiser, B.; Bominaar, E. L.; Yano, J.; Hendrich, M. P.; Borovik, A. S. High-spin Mn-oxo complexes and their relevance to the oxygenevolving complex within photosystem II. Proc. Natl. Acad. Sci. U. S. A. 2015, 112, 53195324. 
(29) Zlatar, M.; Gruden, M.; Vassilyeva, O. Y.; Buvaylo, E. A.; Ponomarev, A. N.; Zvyagin, S. A.; Wosnitza, J.; Krzystek, J.; Garcia-Fernandez, P.; Duboc, C. Origin of the Zero-Field Splitting in Mononuclear Octahedral $\mathrm{Mn}^{\mathrm{IV}}$ Complexes: A Combined Experimental and Theoretical Investigation. Inorg. Chem. 2016, 55, 1192-1201.

(30) Leto, D. F.; Massie, A. A.; Colmer, H. E.; Jackson, T. A. X-Band Electron Paramagnetic Resonance Comparison of Mononuclear $\mathrm{Mn}^{\mathrm{IV}}$-oxo and $\mathrm{Mn}^{\mathrm{IV}}$-hydroxo Complexes and Quantum Chemical Investigation of $\mathrm{Mn}^{\mathrm{IV}}$ Zero-Field Splitting. Inorg. Chem. 2016, 55, 3272-3282.

(31) Oswald, V. F.; Weitz, A. C.; Biswas, S.; Ziller, J. W.; Hendrich, M. P.; Borovik, A. S. Manganese-Hydroxido Complexes Supported by a Urea/Phosphinic Amide Tripodal Ligand. Inorg. Chem. 2018, 57, 13341-13350. 